\title{
Measurement Error in Monetary Aggregates: A Markov Switching Factor Approach
}

\author{
by \\ William Barnett, Marcelle Chauvet, and Heather L. R. Tierney ${ }^{*}$
}

August 6, 2008

\begin{abstract}
This paper compares the different dynamics of the simple sum monetary aggregates and the Divisia monetary aggregate indexes over time, over the business cycle, and across high and low inflation and interest rate phases. Although traditional comparisons of the series sometimes suggest that simple sum and Divisia monetary aggregates share similar dynamics, there are important differences during certain periods, such as around turning points. These differences cannot be evaluated by their average behavior. We use a factor model with regime switching. The model separates out the common movements underlying the monetary aggregate indexes, summarized in the dynamic factor, from individual variations in each individual series, captured by the idiosyncratic terms. The idiosyncratic terms and the measurement errors reveal where the monetary indexes differ. We find several new results. In general, the idiosyncratic terms for both the simple sum aggregates and the Divisia indexes display a business cycle pattern, especially since 1980 . They generally rise around the end of high interest rate phases a couple of quarters before the beginning of recessions - and fall during recessions to subsequently converge to their average in the beginning of expansions. We find that the major differences between the simple sum aggregates and Divisia indexes occur around the beginnings and ends of economic recessions, and during some high interest rate phases. We note the inferences' policy relevance, which is particularly dramatic at the broadest (M3) level of aggregation. Indeed, as Belongia (1996) has observed in this regard, "measurement matters."
\end{abstract}

KEY WORDS: Measurement error, monetary aggregation, Divisia index, aggregation, state space, Markov switching, monetary policy, index number theory, factor models.

JEL Classification Code: E40, E52, E58

\footnotetext{
*William Barnett, Department of Economics, University of Kansas, Lawrence, Kansas 66045-7585; barnett@ku.edu; phone: (785) 864-2844; fax:(785) 864-5760. Marcelle Chauvet, Department of Economics, University of California, Riverside, CA 92521-0247; email: chauvet@ucr.edu; phone: (951) 827-1587; fax: (951) 827-5685. Heather L.R. Tierney, School of Business and Economics, College of Charleston; 5 Liberty Street, Charleston, SC 29424, email: tierneyh@cofc.edu; phone: (843) 953-7070; fax: (843) 953-5697.
} 


\section{Introduction}

There is a vast literature on the appropriateness of aggregating over monetary asset components using simple summation. Linear aggregation can be based on Hickisian aggregation (Hicks 1946), but that theory only holds under the unreasonable assumption that the user-cost prices of the services of individual money assets do not change over time. This condition implies that each asset is a perfect substitute for the others within the set of components. Simple sum aggregation is an even more severe special case of that highly restrictive, linear aggregation, since simple summation requires that the coefficients of the linear aggregator function all be the same. This, in turn, implies that the constant user-cost prices among monetary assets be exactly equal to each other. Not only must the assets be perfect substitutes, but must be perfect one-for-one substitutes --- i.e., must be indistinguishable assets, with one unit of each asset being a perfect substitute for exactly one unit of each of the other assets.

In reality, financial assets provide different services, and each such asset yields its own particular rate of return. As a result, the user costs, which measure foregone interest and thereby opportunity cost, are not constant and are not equal across financial assets. The relative prices of U.S. monetary assets fluctuate considerably, and the interest rates paid on many monetary assets are not equal to the zero interest rate paid on currency. These observations have motivated serious concerns about the reliability of the simple sum aggregation method, which has been disreputable in the literature on index number theory and aggregation theory for over a century. In addition, an increasing number of imperfect substitute short-term financial assets have emerged in recent decades. Since monetary aggregates produced from simple summation do not accurately measure the quantities of monetary services chosen by optimizing agents, shifts in the series can be spurious, as those shifts do not necessarily reflect a change in the utility derived from money holdings.

Microeconomic aggregation theory offers an appealing alternative approach to the definition of money, compared to the atheoretical simple-sum method. The quantity index under the aggregation theoretic approach extracts and measures the income effects of changes in relative prices and is invariant to substitution effects, which do not alter utility and thereby do not alter perceived services received. The simple sum index, on the other hand, does not distinguish between income and substitution effects, if the aggregate's components are not perfect substitutes in identical ratios, and thereby the simple sum index confounds together substitution effects with actual services received. The aggregation-theoretic monetary aggregator function, which correctly internalizes substitution effects, can be tracked accurately by the Divisia quantity index, constructed by using expenditure shares as the component growth-rate weights. Barnett 
$(1978,1980)$ derived the formula for the theoretical user-cost price of a monetary asset, needed in computation of the Divisia index's share weights, and thereby originated the Divisia monetary aggregates. The growth rate weights resulting from this approach are different across assets, depending on all of the quantities and interest rates in each share, and those weights can be timevarying at each point in time. For a detailed description of the theory underlying this construction, see Barnett (1982,1987).

It is important to understand that the direction in which an asset's growth-rate weight will change with an interest rate change is not predictable in advance. Consider Cobb-Douglas utility. Its shares are independent of relative prices, and hence of the interest rates within the component user cost prices. For other utility functions, the direction of the change in shares with a price change, or equivalently with an interest rate change, depends upon whether the own price elasticity of demand exceeds or is less than -1 . In elementary microeconomic theory, this often overlooked phenomenon produces the famous "diamonds versus water paradox" and is the source of most of the misunderstandings of the Divisia monetary aggregates' weighting, as explained by Barnett (1983).

Several authors have studied the empirical properties of the Divisia index compared with the simple sum index. The earliest comparisons are in Barnett (1982) and Barnett, Offenbacher, and Spindt (1984). More recent examples include Belongia (1996), Belongia and Ireland (2006), and Schunk (2001), and the comprehensive survey found in Barnett and Serletis (2000). In particular, Belongia (1996) replicates some studies on the impact of money on economic activity and compares results acquired using a Divisia index instead of the originally used simple sum index, Schunk (2001) investigates the forecasting performance of the Divisia index compared with the simple sum aggregates, and Belongia and Ireland (2006) explore the policy implications in the dual space of aggregated user costs and interest rates. Barnett and Serletis (2000) collect together and reprint seminal journal articles from this literature. ${ }^{1}$

In this paper we compare the different dynamics of simple sum monetary aggregates and the Divisia indexes, not only over time, but also over the business cycle and across high and low inflation and interest rate phases. The potential differences between the series can be economically very important. If one of the indexes corresponds to a better measure of money, its dynamical differences from the official simple sum aggregates increase the already considerable uncertainty regarding the effectiveness and appropriateness of current monetary policy. We aim to study the differences and whether they occur during particular periods. Information about the

\footnotetext{
${ }^{1}$ Other overviews of published theoretical and empirical results in this literature are available in Barnett, Fisher, and Serletis (1992) and Serletis (2006).
} 
state of monetary growth becomes particularly relevant for policymakers, when inflation enters a high growth phase or the economy begins to weaken. In fact Barnett (1997) has argued and documented the connection between the decline in the policy credibility of monetary aggregates and defects that are peculiar to simple sum aggregation.

Although traditional comparisons of the series sometimes suggest that they share similar long run dynamics, there are differences during certain important periods, such as around turning points. These differences cannot be evaluated by long run average behavior. Our proposed approach offers several ways in which these differences can be analyzed. A nonlinear dynamic factor model is used to separate out the common movements underlying the monetary aggregate indexes, summarized in the latent dynamic factor, from individual variations specific to each of the indexes, captured by the idiosyncratic terms. The idiosyncratic terms and the measurement errors reveal where the monetary indexes differ. ${ }^{2}$ The idiosyncratic terms show the movements that are peculiar to each series, whereas the measurement error captures the remaining noise inherent in the data. That is, the dynamic factor represents simultaneous downturn and upturn movements in money growth rate indexes. If only one of the indexes declines, this would be captured by its idiosyncratic term.

We model both the common factor as well as the idiosyncratic terms for each index as following different Markov processes. Given that the idiosyncratic movements are peculiar to each index, the idiosyncratic terms’ Markov processes are assumed to be independent of each other. In addition, we allow the idiosyncratic terms to follow autoregressive processes. These assumptions entail a very flexible framework that can capture the dynamics of the differences across the indexes without imposing dependence between them.

Factor models with regime switching have been widely used to represent business cycles (see e.g., Chauvet 1998, 2001, Kim and Nelson 1998, among several others), but without relationship to aggregation theory. Our proposed model differs from the literature in its complexity, as it includes estimation of the parameters of three independent Markov processes. In addition, the

\footnotetext{
${ }^{2}$ In aggregation theory measurement error refers to the tracking error in a nonparametric index number's approximation to the aggregator function of microeconomic theory, where the aggregator function is the subutility or subproduction function that is weakly separable within tastes or technology of an economic agent's complete utility or production function. Consequently, aggregator functions are increasing and concave and need to be estimated econometrically. On the other hand, state space models use the term measurement error to mean un-modeled noise, which is not captured by the state variable or idiosyncratic terms. In this paper, measurement error refers to this latter definition, which can be expected to be correlated with the former, when the behavior of the data process is consistent with microeconomic theory. But it should be acknowledged that neither concept of measurement error can be directly derived from the other. In fact the state space model concept of measurement error is more directly connected with the statistical ("atomistic") approach to index number theory than to the more recent "economic approach," which is at its best when data is not aggregated over economic agents.
} 
focus is not only on the estimated common factor, but on the idiosyncratic terms that reflect the divergences between the monetary aggregate indexes in a manner relevant to aggregation theory.

To our knowledge, there is no parallel work in the literature that formally compares simple sum aggregate with the Divisia index directly, using a multivariate time-series framework to estimate the dynamical differences between these series. Our contribution goes beyond the simple comparison over time, as we also focus on major measurement errors that might have occurred during some periods, such as around the beginnings or ends of recessions or in transition times, as from low (high) to high (low) inflation or interest rate phases.

We estimate three models, one for each pair of the monetary indexes: simple sum $\mathrm{M}_{1}$ and Divisia $\mathrm{MSI}_{1}$ (Model 1), simple sum $\mathrm{M}_{2}$ and Divisia $\mathrm{MSI}_{2}$ (Model 2), and simple sum $\mathrm{M}_{3}$ and Divisia $\mathrm{MSI}_{3}$ (Model 3), where MSI is the monetary services index computed from the Divisia index by the St. Louis Federal Reserve Bank. Our findings confirm some of the findings of the previous literature in addition to producing several new results.

In general, the idiosyncratic terms for both the simple sum aggregates and the Divisia indexes display a business cycle pattern, especially since 1980. They generally rise around the end of high interest rate phases - a couple of quarters before the beginning of recessions - and fall during recessions to converge subsequently to their average behavior during the beginnings of expansions. We find that the major differences between the simple sum aggregates and Divisia indexes occur around the beginnings and ends of economic recessions, and during some high interest rate phases. This is particularly the case for the period between 1977 and 1983, which includes a slowdown, two recessions, two recoveries, and the change in the Federal Reserve's operating procedure during the "monetarist experiment” period. Notice that this period also corresponds to a high interest rate phase. Another time during which we find that the indexes diverge substantially is around the 1990 recession. A more detailed summary of findings is found in section 4.

\section{Monetary Aggregation Theory}

\subsection{Monetary Aggregation}

Aggregation theory and index-number theory have been used to generate official governmental data since the 1920s. One exception still exists. The monetary quantity aggregates and interest rate aggregates supplied by many central banks are not based on index-number or aggregation theory, but rather are the simple unweighted sums of the component quantities and the quantity-weighted or arithmetic averages of interest rates. The predictable consequence has 
been induced instability of money demand and supply functions, and a series of 'puzzles' in the resulting applied literature. In contrast, the Divisia monetary aggregates, originated by Barnett (1980), are derived directly from economic index-number theory. Financial aggregation and index number theory was first rigorously connected with the literature on microeconomic aggregation and index number theory by Barnett (1980; 1987).

Data construction and measurement procedures imply the theory that can rationalize the aggregation procedure. The assumptions implicit in the data construction procedures must be consistent with the assumptions made in producing the models within which the data are to be used. Unless the theory is internally consistent, the data and its applications are incoherent. Without that coherence between aggregator function structure and the econometric models within which the aggregates are embedded, stable structure can appear to be unstable. This phenomenon has been called the ‘Barnett critique’ by Chrystal and MacDonald (1994).

\subsection{Aggregation Theory versus Index Number Theory}

The exact aggregates of microeconomic aggregation theory depend on unknown aggregator functions, which typically are utility, production, cost, or distance functions. Such functions must first be econometrically estimated. Hence the resulting exact quantity and price indexes become estimator- and specification-dependent. This dependency is troublesome to governmental agencies, which therefore view aggregation theory as a research tool rather than a data construction procedure.

Statistical index-number theory, on the other hand, provides indexes which are computable directly from quantity and price data, without estimation of unknown parameters. Within the literature on aggregation theory, such index numbers depend jointly on prices and quantities, but not on unknown parameters. In a sense, index number theory trades joint dependency on prices and quantities for dependence on unknown parameters. Examples of such statistical index numbers are the Laspeyres, Paasche, Divisia, Fisher ideal, and Törnqvist indexes.

The loose link between index number theory and aggregation theory was tightened, when Diewert (1976) defined the class of second-order 'superlative' index numbers, which track any unknown aggregator function up to the second order. Statistical index number theory became part of microeconomic theory, as economic aggregation theory had been for decades, with statistical index numbers judged by their non-parametric tracking ability to the aggregator functions of aggregation theory.

For decades, the link between statistical index number theory and microeconomic 
aggregation theory was weaker for aggregating over monetary quantities than for aggregating over other goods and asset quantities. Once monetary assets began yielding interest long ago, monetary assets became imperfect substitutes for each other, and the 'price' of monetary-asset services was no longer clearly defined. That problem was solved by Barnett (1978; 1980), who derived the formula for the user cost of demanded monetary services. ${ }^{3}$

Barnett's results on the user cost of the services of monetary assets set the stage for introducing index number theory into monetary economics.

\subsection{The Economic Decision}

Consider a decision problem over monetary assets. The decision problem will be defined in the simplest manner that renders the relevant literature on economic aggregation over goods immediately applicable. ${ }^{4}$ Initially we shall assume perfect certainty.

Let $\mathbf{m}_{t}{ }^{\prime}=\left(m_{1 t}, m_{2 t}, \ldots, m_{n t}\right)$ be the vector of real balances of monetary assets during period $t$, let $\boldsymbol{r}_{t}$ be the vector of nominal holding-period yields for monetary assets during period $t$, and let $R_{t}$ be the one period holding yield on the benchmark asset during period $t$. The benchmark asset is defined to be a pure investment that provides no services other than its yield, $R_{t}$, so that the asset is held solely to accumulate wealth. Thus, $R_{t}$ is the maximum holding period yield in the economy in period $t$.

Let $y_{t}$ be the real value of total budgeted expenditure on monetary services during period $t$. Under simplifying assumptions for data within one country, the conversion between nominal and real expenditure on the monetary services of one or more assets is accomplished using the true cost of living index on consumer goods. ${ }^{5}$ The optimal portfolio allocation decision is:

maximize $u\left(\mathbf{m}_{t}\right)$

\footnotetext{
${ }^{3}$ Subsequently Barnett (1987) derived the formula for the user cost of supplied monetary services. A regulatory wedge can exist between the demand and supply-side user costs, if non-payment of interest on required reserves imposes an implicit tax on banks.

${ }^{4}$ Our research in this paper is not dependent upon this simple decision problem, as shown by Barnett (1987), who proved that the same aggregator function and index number theory applies, regardless of whether the initial model has money in the utility function, or money in a production function, or neither, so long as there is intertemporal separability of structure and certain assumptions are satisfied for aggregation over economic agents. The aggregator function is the derived function that has been shown in general equilibrium always to exist, if money has positive value in equilibrium, regardless of the motive for holding money. See, e.g., Arrow and Hahn (1971), Stanley Fischer (1974), Phlips and Spinnewyn (1982), and Poterba and Rotemberg (1987). Analogously, Feenstra (1986, p. 271) demonstrated "a functional equivalence between using real balances as an argument of the utility function and entering money into liquidity costs which appear in the budget constraints.” The converse mapping from the money in the aggregator (utility or production) function approach to the explicit motive is not unique, but in this paper we are not seeking to identify the motives for holding money.

${ }^{5}$ The multilateral open economy extension is available in Barnett (2007).
} 
subject to $\boldsymbol{\pi}_{t}{ }^{\prime} \mathbf{m}_{t}=\mathrm{y}_{\mathrm{t}}$

where $\boldsymbol{\pi}_{t}{ }^{\prime}=\left(\pi_{l t}, \ldots, \pi_{n t}\right)$ is the vector of monetary-asset real user costs, with

$$
\pi_{i t}=\frac{R_{t}-r_{i t}}{1+R_{t}}
$$

The function $u$ is the decision maker's utility function, assumed to be monotonically increasing and strictly concave. ${ }^{6}$ The user cost formula (2), derived by Barnett (1978; 1980), measures the forgone interest or opportunity cost of holding monetary asset $i$, when the higher yielding benchmark asset could have been held.

Let $\mathbf{m}_{t}^{*}$ be derived by solving decision (1). Under the assumption of linearly homogeneous utility, the exact monetary aggregate of economic theory is the utility level associated with holding the portfolio, and hence is the optimized value of the decision's objective function:

$$
M_{t}=u\left(\mathbf{m}_{t}^{*}\right)
$$

\subsection{The Divisia Index}

Although equation (3) is exactly correct, it depends upon the unknown function, $u$. Nevertheless, statistical index-number theory enables us to track $M_{t}$ exactly without estimating the unknown function, $u$. In continuous time, the monetary aggregate, $M_{t}=u\left(\mathbf{m}_{t}^{*}\right)$, can be tracked exactly by the Divisia index, which solves the differential equation

$$
\frac{d \log M_{t}}{d t}=\sum_{\mathrm{i}} s_{i t} \frac{d \log m_{i t}^{*}}{d t}
$$

for $M_{t}$, where

$$
s_{i t}=\frac{\pi_{i t} m_{i t}^{*}}{y_{t}}
$$

is the $i^{\prime}$ th asset's share in expenditure on the total portfolio's service flow. ${ }^{7}$ The dual user cost

\footnotetext{
${ }^{6}$ To be an admissible quantity aggregator function, the function $u$ must be weakly separable within the consumer's complete utility function over all goods and services. Producing a reliable test for weak separability is the subject of much intensive research, most recently by Barnett and Peretti (2008).

${ }^{7}$ In equation (4), it is understood that the result is in continuous time, so the time subscripts are a short hand for functions of time. We use $t$ to be the time period in discrete time, but the instant of time in continuous time.
} 
price aggregate $\Pi_{t}=\Pi\left(\pi_{t}\right)$, can be tracked exactly by the Divisia price index, which solves the differential equation

$$
\frac{d \log \Pi_{t}}{d t}=\sum_{\mathrm{i}} s_{i t} \frac{d \log \pi_{i t}}{d t}
$$

The user cost dual satisfies Fisher's factor reversal in continuous time:

$$
\Pi_{t} M_{t}=\boldsymbol{\pi}_{t}^{\prime} \mathbf{m}_{t}
$$

As a formula for aggregating over quantities of perishable consumer goods, that index was first proposed by François Divisia (1925), with market prices of those goods inserted in place of the user costs in equation (4). In continuous time, the Divisia index, under conventional neoclassical assumptions, is exact. In discrete time, the Törnqvist approximation is:

$$
\log M_{t}-\log M_{t-1}=\sum_{\mathrm{i}} \bar{s}_{i t}\left(\log m_{i t}^{*}-\log m_{i, t-1}^{*}\right)
$$

where

$$
\bar{s}_{i t}=\frac{1}{2}\left(s_{i t}+s_{i, t-1}\right) .
$$

In discrete time, we often call equation (7) simply the Divisia quantity index. ${ }^{8}$ After the quantity index is computed from (7), the user cost aggregate most commonly is computed directly from equation (6).

\subsection{Risk Adjustment}

Extension of index number theory to the case of risk was introduced by Barnett, Liu and Jensen (2000), who derived the extended theory from Euler equations rather than from the perfect-certainty first-order conditions used in the earlier index number-theory literature. Since that extension is based upon the consumption capital-asset-pricing model (CCAPM), the extension is subject to the 'equity premium puzzle' of smaller-than-necessary adjustment for risk. We believe that the under-correction produced by CCAPM results from its assumption of intertemporal blockwise strong separability of goods and services within preferences. Barnett and $\mathrm{Wu}$ (2005) have extended Barnett, Liu, and Jensen’s result to the case of risk aversion with

\footnotetext{
${ }^{8}$ Diewert (1976) defines a 'superlative index number' to be one that is exactly correct for a quadratic approximation to the aggregator function. The discretization (7) to the Divisia index is in the superlative class, since it is exact for the quadratic translog specification to an aggregator function.
} 
intertemporally non-separable tastes. $^{9}$

\subsection{Dual Space}

User cost aggregates are duals to monetary quantity aggregates. Either implies the other uniquely. In addition, user-cost aggregates imply the corresponding interest-rate aggregates uniquely. The interest-rate aggregate $r_{t}$ implied by the user-cost aggregate $\Pi_{t}$ is the solution for $r_{t}$ to the equation:

$$
\frac{R_{t}-r_{t}}{1+R_{t}}=\Pi_{t}
$$

Accordingly, any monetary policy that operates through the opportunity cost of money (that is, interest rates) has a dual policy operating through the monetary quantity aggregate, and vice versa. Aggregation theory implies no preference for either of the two dual policy procedures or for any other approach to policy, so long as the policy does not violate principles of aggregation theory. In our current state-space comparisons, we model in quantity space rather than the usercost-price or interest-rate dual spaces. Regarding policy in the dual space, see Barnett (1987) and Belongia and Ireland (2006).

\section{The State Space Model}

Let $\mathbf{Y}_{\mathrm{t}}$ be the $n \mathrm{x} 1$ vector of monetary indexes, where $\mathrm{n}$ is the number of monetary indexes in the model.

$$
\Delta \mathbf{Y}_{\mathrm{t}}=\lambda \Delta F_{t}+\gamma \tau_{\mathrm{t}}+\mathbf{v}_{\mathrm{t}}
$$

where $\Delta=1-\mathrm{L}$ and $\mathrm{L}$ is the lag operator. Changes in the monetary aggregates, $\Delta \mathbf{Y}_{\mathrm{t}}$, are modeled as a function of a scalar unobservable factor that summarizes their commonalities, $\Delta F_{\mathrm{t}}$, an idiosyncratic component $n \times 1$ vector, which captures the movements peculiar to each index, $\mathbf{v}_{\mathrm{v}}$ and a potential time trend $\tau_{\mathrm{t}}$. The factor loadings, $\lambda$, measure the sensitivity of the series to the

\footnotetext{
${ }^{9}$ The Federal Reserve Bank of St. Louis Divisia database, which we use in this paper, is not risk corrected. In addition, it is not adjusted for differences in marginal taxation rates on different asset returns or for sweeps, and its clustering of components into groups was not based upon tests of weak separability, but rather on the Federal Reserve's official clustering. The St. Louis Federal Reserve Bank is in the process of revising its MSI database, perhaps to incorporate some of those adjustments. Regarding sweep adjustment, see Jones, Dutkowsky, and Elger (2005). At the present stage of this research, we felt it was best to use data publicly available from the Federal Reserve, so we did not modify the St. Louis Federal Reserve's MSI database in any ways.
} 
dynamic factor, $\Delta F_{\mathrm{t} .}{ }^{10}$ Both the dynamic factor and the idiosyncratic terms follow autoregressive processes:

$$
\begin{array}{ll}
\Delta F_{\mathrm{t}}=\alpha_{S_{t}}+\phi(\mathrm{L}) \Delta F_{\mathrm{t}-1}+\eta_{\mathrm{t}} & \eta_{\mathrm{t}} \sim \mathrm{N}\left(0, \sigma^{2}\right), \\
\mathbf{v}_{\mathrm{t}}=\boldsymbol{\Gamma}_{S_{t}^{h}}+\mathbf{d}(\mathrm{L}) \mathbf{v}_{\mathrm{t}-1}+\boldsymbol{\varepsilon}_{\mathrm{t},} & \boldsymbol{\varepsilon}_{\mathrm{t}} \sim \text { i.i.d. } \mathrm{N}(0, \Sigma),
\end{array}
$$

where $\eta_{\mathrm{t}}$ is the common shock to the latent dynamic factor, and $\varepsilon_{\mathrm{t}}$ are the measurement errors. In order to capture potential nonlinearities across different monetary regimes, the intercept of the monetary factor switches regimes according to a Markov variable, $S_{\mathrm{t}}$, where $\alpha_{S_{t}}=\alpha_{0}+\alpha_{1} S_{t}^{\alpha}$, and $S_{t}^{\alpha}=0,1$. That is, monetary indexes can either be in an expansionary regime, where the mean growth rate of money is positive ( $S_{t}^{\alpha}=1$ ), or in a contractionary phase with a lower or negative mean growth rate $\left(S_{t}^{\alpha}=0\right)$.

We also assume that the idiosyncratic terms for each index follow distinct two-state Markov processes, by allowing their drift terms, $\boldsymbol{\Gamma}_{\mathrm{s}_{\mathrm{t}}^{\mathrm{h}}}$, to switch between regimes. For example, in the case of two monetary indexes, $n=2$, there will be two idiosyncratic terms, each one following an independent Markov process $S_{t}^{\beta}$ and $S_{t}^{\delta}$, where $S_{t}^{\beta}=0,1$ and $S_{t}^{\delta}=0,1$. Notice that we do not constraint the Markov variables $S_{t}^{\alpha}, S_{t}^{\beta}$, and $S_{t}^{\delta}$ to be dependent of each other, but allow them instead to move according to their own dynamics. In fact, there is no reason to expect that the idiosyncratic terms would move in a similar manner to each other or to the dynamic factor, since by construction they represent movements peculiar to each index not captured by the common factor.

The switches from one state to another is determined by the transition probabilities of the first-order two-state Markov processes, $p_{i j}^{k}=\mathrm{P}\left(S_{t}^{k}=j \mid S_{t-1}^{k}=i\right)$, where $\sum_{j=0}^{1} p_{i j}^{k}=1, i, j=0,1$, with $k=\alpha, \beta, \delta$ identifying the Markov processes for the dynamic factor and the two idiosyncratic terms, respectively.

The model separates out the common signal underlying the monetary aggregates from individual variations in each of the indexes. The dynamic factor captures simultaneous downturns and upturns in money growth indexes. On the other hand, if only one of the variables declines, e.g. M1, this would not characterize a general monetary contraction in the model and would be captured by the M1 idiosyncratic term. A general monetary contraction (expansion) will occur

\footnotetext{
${ }^{10}$ The factor loading for the Divisia monetary index series is set equal to one to provide a scale for the latent dynamic factor. This normalization is a necessary condition for identification of the factor, and the choice of parameter scale does not affect any of the time series properties of the dynamic factor or the correlation with its components.
} 
when all $n$ variables decrease (increase) at about the same time. That is, $\eta_{\mathrm{t}}$ and $\mathbf{v}_{\mathrm{t}}$ are assumed to be mutually independent at all leads and lags for all $n$ variables, and $\mathbf{d}(\mathrm{L})$ is diagonal. The dynamic factor is the outcome of averaging out the discrete states. Although the $n$ monetary indexes represent different measurements of money, the estimated dynamic factor is a nonlinear combination of them, representing broader movements in monetary aggregates in the U.S. On the other hand, once a contraction or expansion is clearly under way, the idiosyncratic term for a particular aggregate can be highly informative near a turning point.

Dynamic factor models with regime switching have been widely used to represent business cycles. The proposed model differs from the literature in its complexity, as it includes estimation of the parameters of three independent Markov processes.

The model is cast in state space form, where (11) and (12) are the measurement and transition equations, respectively:

$$
\begin{aligned}
& \Delta \mathbf{Y}_{\mathrm{t}}=\mathbf{Z} \boldsymbol{\xi}_{\mathrm{t}}+\mathbf{G} \tau_{\mathrm{t}} \\
& \xi_{\mathrm{t}}=\boldsymbol{\mu}_{\xi_{s t}}+\mathbf{T} \xi_{\mathrm{t}-1}+\mathbf{u}_{\mathrm{t}} .
\end{aligned}
$$

A particular state space representation for the estimated indicator using two variables is:

$$
\begin{aligned}
& \Delta \mathbf{Y}_{\mathrm{t}}=\left[\begin{array}{c}
\Delta Y_{1 t} \\
\Delta Y_{2 t}
\end{array}\right], \quad \mathbf{Z}=\left[\begin{array}{cccc}
\lambda_{1} & 1 & 0 & 0 \\
1 & 0 & 1 & 0
\end{array}\right], \quad \xi_{\mathrm{t}}=\left[\begin{array}{c}
\Delta F_{t} \\
v_{1 t} \\
v_{2 t} \\
F_{t-1}
\end{array}\right] \boldsymbol{\mu}_{\xi_{s t}}=\left[\begin{array}{c}
\alpha_{s t} \\
\beta_{s t} \\
\delta_{s t} \\
0
\end{array}\right], \\
& \mathbf{T}=\left[\begin{array}{cccc}
\phi_{1} & 0 & 0 & 0 \\
0 & d_{1} & 0 & 0 \\
0 & 0 & d_{2} & 0 \\
1 & 0 & 0 & 1
\end{array}\right], \quad \mathbf{G}=\left[\begin{array}{c}
\gamma_{1} \\
\gamma_{2}
\end{array}\right] \text { and } \quad \mathbf{u}_{\mathrm{t}}=\left[\begin{array}{c}
\eta_{t} \\
\varepsilon_{1 t} \\
\varepsilon_{2 t} \\
0
\end{array}\right] .
\end{aligned}
$$

The term $F_{\mathrm{t}-1}$ is included in the state vector to allow estimation of the dynamic factor in levels from the identity $\Delta F_{\mathrm{t}-1}=F_{\mathrm{t}-1}-F_{\mathrm{t}-2}$.

The model is estimated using an extended version of the nonlinear Kalman filter to compute the latent dynamic factor and each one of three Markov processes. The nonlinear filter forms forecasts of the unobserved state vector, $\xi_{\mathrm{t} \mid \mathrm{t}-1}^{(\mathrm{i}, \mathrm{j})}$, and the associated mean squared error matrices, $\boldsymbol{\theta}_{\mathrm{t} \mid \mathrm{t}-1}^{(\mathrm{i}, \mathrm{j})}$, based on information, $I_{t-1} \equiv\left[\Delta \mathbf{Y}_{\mathrm{t}-1}^{\prime}, \Delta \mathbf{Y}_{\mathrm{t}-2, \ldots,}^{\prime}, \Delta \mathbf{Y}_{1}^{\prime}\right]^{\prime}$, available up to time t-1 on the Markov state $S_{t}$, with each $S_{t}=S_{t}^{\alpha}, S_{t}^{\beta}$, $S_{t}^{\delta}$ taking on the value $j$, and $S_{t-1}$ taking on the value $i$, for $i, j=$ 0,1 :

$$
\xi_{\mathrm{t} \mid \mathrm{t}-1}^{(\mathrm{i}, \mathrm{j})}=E\left(\xi_{\mathrm{t}} \mid I_{\mathrm{t}-1}, S_{\mathrm{t}}=j, S_{\mathrm{t}-1}=\mathrm{i}\right)
$$




$$
\left.\theta_{\mathrm{t} \mid \mathrm{t}-1}^{(\mathrm{i}, \mathrm{j})}=E\left[\left(\xi_{\mathrm{t}}-\xi_{\mathrm{tt|}-1}\right)\left(\xi_{\mathrm{t}}-\xi_{\mathrm{tt|}-1}\right)^{\prime} \mid I_{t-1}, S_{t}=j, S_{t-1}=i\right)\right] .
$$

The filter uses as inputs the joint probability of the Markov-switching states at time $t$-1 and $t$, conditional on information up to $t-1, P\left(S_{t-1}=i, S_{t}=j \mid I_{t-1}\right)$; an inference $\xi_{\mathrm{t}-1 \mid \mathrm{t}-1}^{(\mathrm{i}, \mathrm{j})}$ about the state vector using information up to $t-1$, given $S_{\mathrm{t}-1}=i$ and $S_{\mathrm{t}}=j$; and the mean squared error matrices, $\left\{\theta_{\mathrm{t}-1 \mid \mathrm{t}-1}^{(\mathrm{i}, \mathrm{j})}\right\}$. The outputs are their one-step updated values. The nonlinear Kalman filter is:

$$
\begin{aligned}
& \boldsymbol{\xi}_{\mathrm{t} \mid \mathrm{t}-1}^{(\mathrm{i}, \mathrm{j})}=\boldsymbol{\mu}_{\xi_{s t}}+\mathbf{T} \boldsymbol{\xi}_{\mathrm{t}-1 \mid \mathrm{t}-1}^{\mathrm{i}} \\
& \boldsymbol{\theta}_{\mathrm{t} \mid \mathrm{t}-1}^{(\mathrm{i}, \mathrm{j})}=\mathbf{T} \boldsymbol{\theta}_{\mathrm{t}-1 \mid \mathrm{t}-1}^{\mathrm{i}} \mathbf{T}^{\prime}+\mathbf{H} \\
& \xi_{t \mid t}^{(\mathrm{i}, \mathrm{j})}=\boldsymbol{\xi}_{\mathrm{t} \mid \mathrm{t}-1}^{(\mathrm{i}, \mathrm{j})}+\mathbf{K}_{\mathrm{t}}^{(\mathrm{i}, \mathrm{j})} \mathbf{N}_{\mathrm{t} t \mathrm{t}-1}^{(\mathrm{i}, \mathrm{j})} \\
& \boldsymbol{\theta}_{\mathrm{t} \mid \mathrm{t}}^{(\mathrm{i}, \mathrm{j})}=\left(\mathbf{I}_{n}-\mathbf{K}_{\mathrm{t}}^{(\mathrm{i}, \mathrm{j})} \mathbf{Z}\right) \boldsymbol{\theta}_{\mathrm{t} \mid \mathrm{t}-\mathrm{j}}^{(\mathrm{i}, \mathrm{j})},
\end{aligned}
$$

where $\mathbf{H}$ is the variance-covariance matrix of the vector of disturbances $\mathbf{u}_{\mathrm{t}}, \mathbf{I}_{\mathrm{n}}$ is the identity matrix, $\mathbf{K}_{\mathrm{t}}^{(\mathrm{i}, \mathrm{j})}=\boldsymbol{\theta}_{\mathrm{t} \mid \mathrm{t}-1}^{(\mathrm{i}, \mathrm{j}} \mathbf{Z}^{\prime}\left[\mathbf{Q}_{\mathrm{t}}^{(\mathrm{i}, \mathrm{j})}\right]^{-1}, \mathbf{N}_{\mathrm{t} \mid \mathrm{t}-1}^{(\mathrm{i}, \mathrm{j})}=\Delta \mathbf{Y}_{\mathrm{t}}-\mathbf{Z} \xi_{\mathrm{t} \mid \mathrm{t}-1}^{(\mathrm{i}, \mathrm{j})}$ is the conditional forecast error of $\Delta \mathbf{Y}_{\mathrm{t}}$, and $\mathbf{Q}_{\mathrm{t}}^{(\mathrm{i}, \mathrm{j})}=\mathbf{Z} \boldsymbol{\theta}_{\mathrm{t} \mid \mathrm{t}-1}^{(\mathrm{i}, \mathrm{j})} \mathbf{Z}^{\prime}$ is its conditional variance.

The probability terms are computed using Hamilton's filter, for each $S_{t}=S_{t}^{\alpha}, S_{t}^{\beta}, S_{t}^{\delta}$, as:

$$
P\left(S_{t-1}=i, S_{t}=j \mid I_{t-1}\right)=p^{i j} \sum_{h=0}^{l} P\left(S_{t-2}=h, S_{t-1}=i \mid I_{t-1}\right) .
$$

From these joint conditional probabilities, the density of $\Delta \mathbf{Y}_{\mathrm{t}}$ conditional on $S_{\mathrm{t}-1}, S_{\mathrm{t}}$, and $I_{\mathrm{t}-1}$ is:

$$
f\left(\Delta \mathbf{Y}_{\mathrm{t}} \mid S_{\mathrm{t}-1}=i, S_{t}=j, I_{t-1}\right)=\left[(2 \pi)^{-\mathrm{n} / 2}\left|\mathbf{Q}_{\mathrm{t}}^{(\mathrm{i}, \mathrm{j})}\right|^{-1 / 2} \exp \left(-\frac{1}{2} \mathbf{N}_{\mathrm{t} \mid \mathrm{t}-1}^{(\mathrm{i}, \mathrm{j})} \mathbf{Q}_{\mathrm{t}}^{(\mathrm{i}, \mathrm{j})^{-1}} \mathbf{N}_{\mathrm{t} \mid \mathrm{t}-1}^{(\mathrm{i}, \mathrm{j})}\right) .\right.
$$

The joint probability density of states and observations is then calculated by multiplying each element of (19) by the corresponding element of (20):

$$
f\left(\Delta \mathbf{Y}_{\mathrm{t}}, S_{\mathrm{t}-1}=\mathrm{i}, S_{\mathrm{t}}=\mathrm{j} \mid I_{t-1}\right)=f\left(\Delta \mathbf{Y}_{\mathrm{t}} \mid S_{\mathrm{t}-1}=\mathrm{i}, S_{\mathrm{t}}=\mathrm{j}, I_{\mathrm{t}-1}\right) P\left(S_{\mathrm{t}-1}=\mathrm{i}, S_{\mathrm{t}}=\mathrm{j} \mid I_{\mathrm{t}-1}\right) .
$$

The probability density of $\Delta \mathbf{Y}_{\mathrm{t}}$ given $I_{\mathrm{t}-1}$ is:

$$
f\left(\Delta \mathbf{Y}_{\mathrm{t}} \mid I_{\mathrm{t}-1}\right)=\sum_{j=0}^{1} \sum_{i=0}^{1} f\left(\Delta \mathbf{Y}_{\mathrm{t}}, S_{\mathrm{t}-1}=\mathrm{i}, S_{\mathrm{t}}=\mathrm{j} \mid I_{\mathrm{t}-1}\right)
$$

The joint probability density of states is calculated by dividing each element of (14) by the corresponding element of (22):

$$
P\left(S_{t-1}=i, S_{t}=j \mid I_{t}\right)=f\left(\Delta \mathbf{Y}_{\mathrm{t}}, S_{\mathrm{t}-1}=i, S_{\mathrm{t}}=j \mid I_{\mathrm{t}-1}\right) / f\left(\Delta \mathbf{Y}_{\mathrm{t}} \mid I_{\mathrm{t}-1}\right)
$$

Finally, summing over the states in (23), we obtain the filtered probabilities of expansions or recessions:

$$
P\left(S_{t}=j \mid I_{t}\right)=\sum_{i=0}^{l} P\left(S_{\mathrm{t}-1}=i, S_{\mathrm{t}}=j \mid I_{\mathrm{t}}\right) .
$$


As with the linear Kalman filter, the algorithm calculates recursively one-step-ahead predictions and updates equations of the dynamic factor and the mean squared error matrices, given the parameters of the model and starting values for $\xi_{\mathrm{t} \mid \mathrm{t}}^{\mathrm{j}}, \theta_{\mathrm{t} \mid \mathrm{t}}^{\mathrm{j}}$, and the probabilities of the Markov states. However, for each date $\mathrm{t}$ the nonlinear filter computes $2^{\mathrm{k}}$ forecasts, where $\mathrm{k}$ is the number of states, and at each iteration the number of cases is multiplied by $k$. This implies that the algorithm would be computationally unfeasible, even for the simplest cases. Kim (1994), based on Harrison and Stevens (1976), proposes an approximation introduced through $\xi_{\mathrm{t} \mid \mathrm{t}}^{\mathrm{j}}$ and $\boldsymbol{\theta}_{\mathrm{t} \mid \mathrm{t}}^{\mathrm{j}}$ for $t>1$. This approximation consists of truncating the updating equations into averages weighted by the probabilities of the Markov states.

At each $t$, the conditional likelihood of the observable variables is obtained as a by-product of the algorithm from equation (20), which is used to estimate the unknown model parameters. The filter evaluates this likelihood function, which is then maximized with respect to the model parameters using a nonlinear optimization algorithm. The maximum likelihood estimators and the sample data are then used in a final application of the filter to draw inferences about the dynamic factor and probabilities, based on information available at time $t$. The final estimated state vector is calculated as:

$$
\xi_{\mathrm{t} \mid \mathrm{t}}=\sum_{i=0}^{1} \mathrm{P}\left(S_{t}=j \mid I_{t}\right) \xi_{\mathrm{t} \mid \mathrm{t}}^{\mathrm{j}}
$$

The estimation is implemented through a numerical procedure. The nonlinear discrete filter produces two outputs: the state vector, $\xi_{\mathrm{t} \mid \mathrm{t}}$, containing the dynamic factor and the idiosyncratic terms, along with the associated probabilities of the Markov states. The filtered probabilities give at time $t$ the probability of the Markov state, using only information available at $t, P\left(S_{t}=0,1 \mid I_{t}\right)$. On the other hand, the smoothing probabilities are obtained through backward recursion using the information in the full sample, $P\left(S_{t}=0,1 \mid I_{T}\right)$.

\section{Empirical Results}

\subsection{Data}

We use the federal funds rate as the interest rate in defining high and low interest rate phases and the log first difference of consumer price index as the inflation rate in defining high and low inflation phases. Those two series and the simple sum monetary aggregates, M1, M2, and M3, as well as their corresponding “monetary service indexes” (Divisia), MSI1, MSI2, MSI3, were all obtained from the Federal Reserve Bank of Saint Louis. The Research Division of the Saint 
Louis Federal Bank produces the MSI indexes on a regular basis using equation (7). The MSI Divisia indexes measure the flow of monetary services obtained by households and firms from holding monetary assets. For the theory and methodology utilized in the construction of these indexes, and for details of the construction of these indexes, see Anderson, Jones, and Nesmith (1997a and b). For a survey of the theory of monetary aggregation, empirical comparisons of monetary aggregates, and reprints of seminal papers on the subject, see Barnett and Serletis (2000). We use quarterly data from 1960:2 to 2005:4, which is the sample period during which the Divisia indexes data were available at the time that this research was conducted.

\subsection{Specification Tests}

The dynamic factor structure captures cyclical comovements underlying the observable variables. We find that the resulting dynamic factor is highly correlated with all of the monetary aggregates used in its construction. As a result, it is clear that the structure was not imposed on the data by assuming large idiosyncratic errors.

In addition, tests for the number of states strongly support the single factor specification. This conclusion is tested in different ways. First, the eigenvalues of the correlation matrix of the common factor indicate adequacy of the single factor specification. ${ }^{11}$ Second, the model assumes that the factor summarizes the common dynamic correlation underlying the observable variables. Consequently, the idiosyncratic terms in $\mathbf{v}_{\mathrm{t}}$ are uncorrelated with the observed variables in $\Delta \mathbf{Y}_{\mathrm{t} \cdot}{ }^{12}$ To test this assumption, the idiosyncratic terms $\mathbf{v}_{\mathrm{t}}$ are regressed on six lags of the observable variables $\Delta \mathbf{Y}_{\mathrm{t}}$, and the parameters of the equations are found to be insignificantly different from zero. In addition, the one-step-ahead conditional forecast errors, $\mathbf{N}_{\mathrm{tt} t-1}$, obtained from the filter described in section 2, are not predictable by lags of the observable variables. These results support the single factor specification, since these error terms are not capturing common information underlying the observable variables.

With respect to the measurement errors, $\boldsymbol{\varepsilon}_{\mathrm{t}}$, the i.i.d. assumption is tested using Ljung-Box statistics on their sample autocorrelation and the BDS test proposed by Brock, Dechert, Scheinkman, and LeBaron (1996). ${ }^{13}$ Both tests fail to reject the i.i.d. assumption at any level.

\footnotetext{
11 The magnitude of the $n$ eigenvalues for each factor reflects how much of the correlation among the observable variables is explained by $k \leq n$ potential factors. For each of the three composite indicators, there is only one eigenvalue greater than one, while the others are close to zero.

12 The model was estimated allowing either $\operatorname{AR}(1)$ or $\operatorname{AR}(0)$ processes for the disturbances $\Delta \mathbf{v}_{\mathrm{t}}$. The likelihood ratio test favors the AR(1) specification at the $1 \%$ level.

13 The BDS test requires prior settings of two calibration parameters: embedding dimensions, m, and norm bound, $\varepsilon$. We set $\mathrm{m}=2,3,4,5,6$ months and $\varepsilon=$ standard deviation of the univariate disturbance time series, assumed to have constant mean function and constant conditional variance.
} 


\subsection{High and Low Inflation and Interest Rate Phases}

We study changes in monetary growth across business cycle phases and across high and low inflation and interest rate periods. We use economic recessions and expansions as dated by the NBER to analyze changes across business cycle states. Regarding inflation, we are mostly interested in identifying periods during which there is a persistent change in this series. We classify a high inflation phase as one in which inflation increases persistently for several quarters until it reaches a peak. Analogously, low inflation phases start when inflation falls for several quarters until it reaches a trough. A high (low) inflation phase may include periods during which the level of inflation is still relatively low (high) but is increasing (decreasing) persistently. That is, the level of inflation is not as relevant as its rate of change. For example, inflation was historically low in the early 2000s, but since its derivative turned positive in 2002:1 and remained so for a couple of quarters, this date indicates the beginning of a high inflation phase.

The metric proposed to determine inflation phases is as follows: a high inflation phase starts in quarter $t$, if inflation $\pi_{\mathrm{t}-1}$ was in a low phase in quarter t- 1 and $\pi_{t+2} \geq \pi_{t+1} \geq \pi_{t} \geq \pi_{t-1}$. That is, inflation grows for three consecutive quarters. A low inflation phase starts in quarter $t$, if inflation $\pi_{\mathrm{t}-1}$ was in a high phase in quarter $\mathrm{t}-1$ and $\pi_{t+1}<\pi_{t}<\pi_{t-1}$. That is, inflation falls for two consecutive quarters. This is similar to the rule of thumb of two quarters decrease (increase) in GDP to determine the beginning of recessions (expansions), although we use an asymmetric number of quarters for high and low phases based on inflation persistence. However, the results do not change, if we use instead two quarters decrease or increase.

We also use the Bry and Boschan (1971) routine to determine inflation phases. Bry and Boschan (B-B) formalize turning point dating rules into a computer routine, which has been refined by Haywood (1973) to include an amplitude criterion. ${ }^{14}$ The turning points obtained coincide with our proposed criterion described above. In fact, both methods select turning points that would be easily picked simply by visual inspection of the smoothed series.

The resulting inflation phases are plotted in figure 1a together with inflation, smoothed inflation, and NBER recessions. When inflation starts increasing, it does so slowly and steadily. However, when inflation falls, it drops abruptly, making it easier to identify the beginning of a low inflation phase than the start of a high inflation phase. Notice that inflation phases are associated with NBER recessions. In particular, all recessions begin around the end of high

\footnotetext{
${ }^{14}$ The main steps of the B-B routine are: (1) the data are smoothed after outliers are discarded; (2) preliminary turning points are selected and compared with the ones in the original series; (3) duration of the phases is checked, and if duration is below 6 months, the turning points are disregarded; (4) amplitude criterion is applied, based on a moving standard deviation of the series. In the end, the program selects turning points that would be easily picked simply by visual inspection.
} 
inflation phases. In addition, there were only two high inflation phases, in 1983-1984 and in 2002, during which a recession did not follow. However, the economy entered a slowdown in 1984-1986.

With respect to interest rate, the determination of peaks and troughs is simplified by the fact that this series is smoother than inflation. We use a similar metric to the one used for inflation. However, using two or three quarters of change as the cut off for dating the phases results in exactly the same dating. Thus, we use the following metric: a high interest rate phase starts in quarter $t$, if interest rate $\mathrm{i}_{\mathrm{t}-1}$ was in a low phase in quarter $\mathrm{t}-1$ and if $i_{t+1} \geq i_{t} \geq i_{t-1}$; and a low interest rate phase starts in quarter $t$, if interest rate $\mathrm{i}_{\mathrm{t}-1}$ was in a high phase in quarter $t-1$ and if $i_{t+1}<i_{t}<i_{t-1}$. That is, the turning point of interest rate phases takes place, when the interest rate falls or rises for two consecutive quarters. Once again, we use the Bry and Boschan (1971) routine to determine interest rate phases and find the same turning points as the two-consecutivequarter rule of thumb.

The interest rate phases are shown in figure $1 \mathrm{~b}$ as well as interest rate, smoothed interest rate, and NBER recessions. Interest rate phases are also associated with the NBER recessions and expansions - the peak generally is at, or right before, economic recessions, whereas the trough is roughly in the middle of expansions. One exception is for the most recent expansion, in which the high interest phase started a lot earlier, at the trough of the 2001 recession.

\subsection{Estimates}

Table 1 displays the maximum likelihood estimates of the Markov switching dynamic factor model applied to the monetary aggregates. Three models were estimated, one for each pair of the monetary indexes: $\mathrm{M}_{1}$ and $\mathrm{MSI}_{1}$ (Model 1), $\mathrm{M}_{2}$ and $\mathrm{MSI}_{2}$ (Model 2), and $\mathrm{M}_{3}$ and $\mathrm{MSI}_{3}$ (Model 3).

The Markov states for the factors are statistically significant across the specifications. For models 1 and 3, state 1 has a positive mean growth rate, $\alpha_{1}$, while state 0 has a negative mean growth rate, $\alpha_{0}$. For model 2, the mean growth rates in both states are positive, although the mean growth rate in state 0 is smaller than in state 1 , and they both are statistically significant at the $1 \%$ level.

The autoregressive coefficient for the factor, $\phi$, is positive and near 0.5 across all specifications. The factor loadings measure how changes in the dynamic factor affect changes in the observable variables. The loadings for the Divisia monetary indexes are set equal to one to provide a scale for the latent dynamic factors. This normalization is a necessary condition for identification of the factors. The choice of parameter scale does not affect any of the time series properties of the dynamic factor or the correlation with its components. We find that the 
estimated factor loading for the simple sum monetary aggregate is positive and close to one across all models, indicating that the Divisia index and the simple sum aggregate have a similar and proportional impact on the factor for each model.

All other parameters of the model are statistically significant as well. We discuss their dynamics for each model below.

\subsection{Simple M1 Aggregate and Divisia M1}

The factor extracted from the growth rates of the simple sum aggregate M1 and from the growth rate of the Divisia M1 (MSI1) index is plotted in Figure 2a together with the probabilities of low monetary growth and NBER recessions (DF1). During the 1960s and 1970s, the factor is mostly positive with an average quarterly growth of $1.2 \%$. In the second half of the sample, there are times during which money growth decreases substantially, reaching negative values. The smoothed probabilities identify four phases of negative monetary growth during this second half: 1989:1-1989:4, 1994:4-1997:2, 2000:2-2000:4, and 2005:1-20005:3; and a pulse change in 1980:2.

With correlation values of 0.988 for M1 and 0.998 for MSI1, respectively (Table 2), the dynamic factor is highly correlated with its components. Notice that M1 and MSI1 are more correlated with the factor than with each other. Figure $2 b$ plots these series and NBER recessions. Although the comparison of the series suggests that they share very similar dynamics, there are important differences during certain times and around turning points that cannot be evaluated by their average behavior. The idiosyncratic terms and the measurement errors reveal where the monetary indexes differ.

The idiosyncratic term for MSI1 is highly autocorrelated (0.98) and smooth, whereas the one for M1 is a lot less persistent (0.48) and more jagged (Table 1 and Figure 2c). Both idiosyncratic

terms display a business cycle pattern from 1980 on. In particular, they rise before the beginnings of recessions and fall during recessions, but subsequently converge to their average in the beginnings of expansions. During the 1980s' and 1990s' expansions, the idiosyncratic terms increased steadily until reaching a peak in the middle of these expansions.

Figure 2d plots the squared difference between the idiosyncratic terms for M1 and MSI1, NBER recessions, and phases of high inflation and interest rates. From 1960 until 1976 the difference between them was almost zero. However, analysis of the second part of the sample uncovers some interesting divergent patterns. The major differences took place right around the beginning or end of recessions. Notice that the beginning of recessions is also the end of high interest rate and inflation phases. The largest differences occurred at the end of the 1981-82 recession and in 2005:3, followed by divergences before the 1980-81 and 1981-82 recessions and 
at the trough of the 1990-91 recession. In addition, persistent differences took place during high phases of inflation and interest rates. It can be observed that differences also occur, when there are some major changes in the magnitude of monetary growth. This is especially the case between 1994:4-1997:2, when both the rate of growth of M1 and of the Divisia index, MSI1, decreased substantially to negative values.

Figure 2e shows the measurement error from simple sum aggregate M1 growth, from Divisia M1 growth (MSI1), and NBER recessions. The measurement error from Divisia growth is a lot smaller than from simple sum M1 growth throughout the sample. As discussed in the previous section, linear and nonlinear tests fail to reject the hypothesis of i.i.d. for the measurement errors. However, some interesting patterns can be observed in their squared differences. Since 1984, the measurement error of M1 growth is greater than of Divisia growth in the middle of expansions and smaller from the second half of expansions until around the beginning of recessions. The difference becomes positive during recessions but reverts to negative at their end. The major difference between the two took place in the first quarter of 1983, when the measurement error for M1 growth reached its maximum value.

Figure $2 \mathrm{f}$ shows the squared difference between the measurement errors. As for the idiosyncratic terms, the difference between the measurement errors is almost zero before 1976 . However, its highest levels occurred during the high inflation phase between 1977 and 1983 . It also increased at the peak and trough of the 1990-1991 recession and between 1999 and 2000, during the high inflation and interest rate phase that preceded the 2001 recession. As for the idiosyncratic terms, the only time that the difference between the two measurement errors was large, but not associated with a high inflation or interest rate phase or a recession, was between 1995-1996. This period corresponds to a shift of monetary growth from historically positive to very negative.

This analysis confirms previous results (see e.g. Belongia 1996), which find large differences between M1 and Divisia MSI1 between 1984 and 1987 and between 1995 and 1997, with the former being greater than the latter.

\subsection{Simple M2 Aggregate and Divisia M2}

The dynamic factor obtained from the growth rates of the simple sum aggregate M2 and from the Divisia M2 (MSI2) is highly correlated with these series, with correlations of 0.95 and 0.96, respectively (Table 2). Figure 3a shows this factor (DF2) and the probabilities of high monetary growth. The most noticeable feature of the factor (and of its components) is its rise during 197073 and during 1975-78. These periods are captured by the smoothed probabilities, as well as the fast monetary growth phases following the 1980-81 and 1981-82 recessions, and during the 2001 
recession. Other periods during which money growth was well above its average included 198586 and 1998, as depicted by the probabilities.

The dynamics of the factor DM1 differ substantially from the factor DM2, especially after 1990 (Figures 1c and 3b), and the overall correlation between them is only 0.34. First, the DM1 factor does not increase as substantially as the DM2 factor in the 1970s. Second, the DM2 factor moves in the opposite direction from the DM1 factor during 1991-1994, with DM2 reaching its highest level of growth during this period. A divergent movement also takes place in 1995-1996, when DM1 grows and DM2 falls. This same pattern is found by comparing the growth rate of M1 and MSI1 with M2 and MSI2.

The idiosyncratic terms for M2 and MSI2 are shown in Figure 3c. There are marked differences between them. Although they generally move in the same direction in the first part of the sample, they differ substantially around turning points and in the second period. For example, the idiosyncratic term for M2 increased during the 1970 and 1974-75 recessions, even when interest rate was already in a low phase. The idiosyncratic term for the MSI2, on the other hand, decreased during these periods. From 1982 there are several instances in which these series display divergent movements.

Figure 3d shows the squared difference between these two series along with NBER recessions and phases of high inflation and interest rates. For the most part the discrepancies between the idiosyncratic terms take place during transition times, such as around business cycle turning points or the beginnings and ends of interest rate or inflation phases. The largest differences were from the middle to the trough of the 1980-81 and 1981-82 recessions, at the end of the high interest rate phase in 1989 (and the beginning of an economic slowdown), and between 1991 and 1996. In this last period the differences were not only large, but they were also the longest in the sample, corresponding to cyclical movements of DM1 and DM2 in opposite directions as explained above. There were other important divergences, such as the ones during the 1970 and 1990 recessions, and during the transitions from tight to loose monetary policies.

Figure 3f plots the difference between the measurement errors for M2 and MSI2 growth. The main discrepancies between these two series occur between 1979 and 1982. This period includes a slowdown, two recessions and a small recovery, and coincides with the time during which the Federal Reserve changed its operating procedures.

Another time during which these series differ is in the transition between two phases in 1989. In particular, a large difference takes place at the peak of the interest rates cycle. While interest rate started decreasing in 1989:2, inflation remained in a high phase until 1990:2. 


\subsection{Simple M3 Aggregate and Divisia M3}

Figure 4a shows the dynamic factor (DF3) resulting from the growth rates of the simple sum aggregate M3 and from Divisia M3 (MSI3), while Figure 1c compares the three dynamic factors, DF1, DF2, and DF3. The factor DF1 moves in the opposite direction from the factors DF2 and DF3 during some periods, whereas in general DF2 and DF3 display very similar dynamics (Figure 1c). However, DF3 growth (as well as M3 and MSI3 growth) was not as high in the 1970s as DF2 growth. In fact, the Markov probabilities for DF3 capture instead a large drop in the underlying M3 and MSI3 growth between 1989:2 and 1995:1 as being the most salient variation in the series. Other important low growth phases captured by the probabilities are in 1966, between 1969-70, in 2002, and in 2004-05.

The dynamic factor DF3 is highly correlated with M3 and MSI3 growth, but more so with the former (0.98) than with the latter (0.90) (Table 2). However, the correlation between the dynamic factor and the growth of MSI3 is a lot higher, if the period between 1978 and 1982 is excluded. During this time, MSI3 growth oscillated substantially (Figure 4b).

The idiosyncratic terms for M3 and MSI3 growth are shown in Figure 4c. The term corresponding to M3 is smoother and has smaller fluctuations. Although they have generally similar dynamics, the two idiosyncratic terms differ substantially during some important periods. Figure 4d plots their squared difference. The major divergences between M3 and MSI3 growth coincide in time and amplitude with the differences between M2 and MSI2 growth. The largest discrepancies took place during the high inflation phase between 1978 and 1981, and during the 1981-82 recession. Times of high uncertainty are associated with larger asynchronous movements between M3 and MSI3 growth, such as during recessions or at interest rate turning points. This is the case, for example, between 1989 and 1990, when the high interest rate phase ended, but inflation remained in a high phase until right before the beginning of the 1990 recession. This is also the case in 1965-67, during the 1969-70 and 1990-91 recessions, and during the 1972-74 period, which corresponds to a high inflation phase and recession.

Another way of gauging the differences between M3 and MSI3 growth is through the measurement errors. Figure 4e shows the squared difference between their measurement errors. Analysis of these series indicates that the major differences took place in 1979:4, 1982:1, and in the middle of the 1969-73 recession, in addition to the dissimilarities captured by the idiosyncratic terms. 


\section{Summary of Findings}

These differences are economically very important. If one of the aggregates corresponds to a better measure of economic monetary services in the economy than the other, their differences add to the uncertainty about the economy and about the effectiveness and appropriateness of monetary policy --- exactly at times during which information about the state of monetary growth is premium, such as around business cycle turning points and changes in inflation phases.

In general, the idiosyncratic terms for both the simple sum aggregates and the Divisia indexes display a business cycle pattern, especially since 1980. Those terms generally rise around the end of high interest rate phases (i.e., a couple of quarters before the beginning of recessions), fall during recessions, and subsequently converge to their average in the beginning of expansions.

We find that the major differences between the simple sum aggregates and Divisia indexes occur around the beginnings and ends of economic recessions, and during some high interest rate phases. This is particularly the case for the period between 1977 and 1983, which includes a slowdown, two recessions, two recoveries and the change in the Federal Reserve's operating procedure. Notice that this period also corresponds to a high interest rate phase, which took place from 1977:2 to 1981:2. Another period during which the indexes diverge substantially is around the 1990 recession.

In the case of M1 and MSI1, the main divergence between the two indexes is in 1983:1. The idiosyncratic term for M1 counter-intuitively increased to its highest level during a quarter that marked the beginning of a high interest rate phase. The MSI1, on the other hand, had only a minor rise. At that time, Milton Friedman, based on the movements of the official simple sum monetary aggregates, warned in newspapers and magazines that this 'monetary explosion' was bounded to be followed by a contractionary policy by the Federal Reserve, and thereby would lead to another period of stagflation. William Barnett, on the other hand, correctly predicted that there was no reason for concern, since monetary growth was at its average rate, based on the Divisia index data. In fact, Barnett correctly determined in real time that the large increase in simple sum money was a 'statistical blip' produced by the defects in simple sum monetary aggregation. In fact the two conflicting predictions appeared most dramatically on exactly the same day: September 26, 1983, Newsweek, (Friedman) and September 26, 1983, Forbes (Barnett), both full page articles. ${ }^{15}$

\footnotetext{
${ }^{15}$ This is hardly the only such example of monetary policy puzzles associated with monetary aggregation problems. For more examples, see Barnett (1997) and Barnett and Chauvet (2008). It is perhaps paradoxical that Friedman was mislead by confidence in Federal Reserve monetary aggregates data, since he was highly critical of the Federal Reserve, and since Friedman and Schwartz (1970, pp. 151-152) were among the first to make clear the nature of the Federal Reserve's data aggregation error, when they wrote: “The [simple summation] procedure is a very special case
} 
The differences and similarities between the pairs M2-MSI2 (model 2) and M3-MSI3 (model 3) are closer than the ones for M1 and MSI1 (model 1). First, the Divisia indexes MSI2 and MSI3 decrease a lot more before recessions (at the peak of inflation phases) and increase substantially more during recessions and recoveries (low interest rate phases) than the simple sum aggregates M2 and M3, respectively. That is, the dynamics of these Divisia indexes correspond more closely to the expected movements related to interest rates and inflation.

A noticeable difference between the Divisia MSI2 and the simple sum aggregate M2 is their movement in opposite directions between 1991 and 1995. During the recovery after the 1990 recession, M2 increased more than MSI2, while interest rates were falling. However, M2 continued to increase even during the high interest rate phase that started in 1993:3 and ended in 1995:1. On the other hand, MSI2 showed a movement more consistent with changes in interest rates, which decreased during this period.

Another difference that is observable in both pairs M2-MSI2 and M2-MSI3 is their behavior at the end of the 1981 recession, when there was a large increase in the idiosyncratic terms from the Divisia indexes, and only a minor rise for the simple sum aggregates. Accordingly, the Divisia indexes display a business cycle pattern more consistent with monetary policy.

With respect to MSI3 and the simple sum aggregate M3, the idiosyncratic terms for these series move in opposite directions on several occasions. In particular, this term for the Divisia index increases during the expansion in the early 1970s, while the idiosyncratic term for M3 counter-intuitively decreases. In addition, the idiosyncratic term for M3 shows a steady increase, since the end of the 1981-82 recession until 1989, thereby showing no link with the high interest rate phase that took place during 1986:4-1989:1. On the other hand, the term for MSI3 increased during the low inflation phase following the 1981-82 recession, but fell during this high interest rate phase. More recently, the idiosyncratic term from the M3 has been counter intuitively high during the latest high interest rate phase that started in 2004, whereas the Divisia MSI3 shows the expected decrease.

\section{Conclusions}

Microeconomic aggregation theory offers an appealing alternative to the disreputable simplesum method of aggregation. The quantity index under the aggregation-theoretic approach passes through and measures income effects while internalizing and removing substitution effects, which

of the more general approach. In brief, the general approach consists of regarding each asset as a joint product having different degrees of 'moneyness,' and defining the quantity of money as the weighted sum of the aggregated value of all assets .... We conjecture that this approach deserves and will get much more attention than it has so far received.” 
are at constant utility and hence cannot reflect a change in perceived services. The simple sum index, on the other hand, confounds together income and substitution effects, unless components are one-to-one perfect substitutes, i.e., indistinguishable goods. In this paper we compare the dynamic empirical differences between the theory-based definition of money, tracked nonparametrically by the Divisia index, and the simple sum monetary aggregates, traditionally used by central banks and currently in low repute within the economics profession.

Our focus is not only on differences in their average behavior, but also their behavior during some important periods of time, such as around business cycle turning points and across high and low inflation and interest rate phases. We propose a factor model with regime switching to evaluate the common dynamics of the indexes, as well as their idiosyncratic movements.

The state-space time-series approach provides a highly promising direction for research into aggregation theory, index number theory, and economic policy. In this paper we have introduced the connection between the state-space time-series approach to assessing measurement error and the aggregation theoretic concept, with emphasis upon the relevancy to monetary aggregation and monetary policy.

We find some interesting new results. The idiosyncratic terms for both indexes display a business cycle pattern, especially since 1980. The period between 1977 and 1983 is the one during which the most notable differences take place. This period not only includes a slowdown, two recessions, two recoveries, and the change in the Federal Reserve's operating procedure, but also corresponds to a high interest rate phase, which occurred from 1977:2 to 1981:2.

In general, we find that the major differences between the simple sum aggregates and Divisia indexes occur around the beginnings and ends of economic recessions, and during some high interest rate phases. These are times in which information on monetary aggregates is premium for policymakers.

We would once again wish to draw attention to one especially clear figure: Figure 4c. Properly weighted broad aggregates are the best measures of monetary service flows, as observed by Lucas (2000, p. 270), who wrote: "I share the widely held opinion that M1 is too narrow an aggregate for this period [the 1990s], and I think that the Divisia approach offers much the best prospects for resolving this difficulty.” As a result, those measures that are specific to (i.e., idiosyncratic to) simple sum M3 and Divisia M3 are of particular interest. Compare Divisia M3’s idiosyncratic downward spikes in figure 4c with simple sum M3's idiosyncratic behavior and then compare the relative predictive ability of the two extracted idiosyncratic terms with respect to NBER recessions. Figure 4c speaks for itself. 


\section{References}

Anderson, R., B. Jones, and T. Nesmith , 1997a, "Introduction to the St. Louis Monetary Services Index Project,” Federal Reserve Bank of St. Louis Review, January/February, Vol. 79, No.1, 25-30.

Anderson, R., B. Jones, and T. Nesmith, 1997b, “Building New Monetary Services Indexes: Concepts Data and Methods,” Federal Reserve Bank of St. Louis Review, January/February, Vol. 79, No.1, 53-82.

Arrow, K. J. and G. H. Hahn, 1971. General Competitive Analysis, San Francisco: Holden-Day.

Barnett, William A., 1978. "The User Cost of Money." Economics Letter 1 145-149. Reprinted in William A. Barnett and Apostolos Serletis (eds.), 2000, The Theory of Monetary Aggregation, North Holland, Amsterdam, chapter 1, pp. 6-10.

Barnett, William A., 1980. "Economic Monetary Aggregates: An Application of Aggregation and Index Number Theory," Journal of Econometrics 14, 11-48. Reprinted in William A. Barnett and Apostolos Serletis (eds.), 2000, The Theory of Monetary Aggregation, North Holland, Amsterdam, chapter 1, pp. 6-10.

Barnett, William A., 1982. "The Optimal level of Monetary Aggregation," Journal of Money, Credit, and Banking 14, 687-710. Reprinted in William A. Barnett and Apostolos Serletis (eds.), 2000, The Theory of Monetary Aggregation, North Holland, Amsterdam, chapter 7, pp. 125-149.

Barnett, William A., 1983. "Understanding the New Divisia Monetary Aggregate," Review of Public Data Use 11, 349-355. Reprinted in William A. Barnett and Apostolos Serletis (eds.), 2000, The Theory of Monetary Aggregation, North Holland, Amsterdam, chapter 4, pp. 100108.

Barnett, William A., 1987, “The Microeconomic Theory of Monetary Aggregation, in William A. Barnett and Kenneth Singleton (eds.), New Approaches to Monetary Economics, Cambridge U. Press. Reprinted in William A. Barnett and Apostolos Serletis (eds.), 2000, The Theory of Monetary Aggregation, North Holland, Amsterdam, chapter 3, pp. 49-99.

Barnett, William A., 1997. “Which Road Leads to Stable Money Demand?”, The Economic Journal 107, 1171-1185. Reprinted in William A. Barnett and Apostolos Serletis (eds.), 2000, The Theory of Monetary Aggregation, North Holland, Amsterdam, chapter 24, pp. 577-592.

Barnett, William A., 2007, "Multilateral Aggregation-Theoretic Monetary Aggregation over Heterogeneous Countries,” Journal of Econometrics, vol 136, no 2, February, pp. 457-482.

Barnett, William A. and Marcelle Chauvet, 2008, "A Survey of the Connection between Monetary Aggregation Theory, Bad Data, and the Monetary Policy Puzzles,” working paper.

Barnett, William A. and Philippe de Peretti, 2008. “A Necessary and Sufficient Stochastic SemiNonparametric Test for Weak Separability, Macroeconomic Dynamics, forthcoming. 
Barnett, W. A. and A. Serletis (eds), 2000, The Theory of Monetary Aggregation, Contributions to Economic Analysis Monograph Series, Elsevier, Amsterdam.

Barnett, William A. and Wu, She. 2005. "On user costs of risky monetary assets.” Annals of Finance 1, 35-50.

Barnett, W., Fisher, D. and Serletis, A. 1992. Consumer theory and the demand for money. Journal of Economic Literature 30, 2086-119. Reprinted in Barnett and Serletis (2000, ch. 18).

Barnett, W. A., Liu, Y. and Jensen, M. 2000. CAPM risk adjustment for exact aggregation over financial assets. Macroeconomic Dynamics 1, 485-512.

Barnett, William A., Edward K. Offenbacher, and Paul A. Spindt, 1984. "The New Divisia Monetary Aggregates," Journal of Political Economy 92, 1049-1085. Reprinted in William A. Barnett and Apostolos Serletis (eds.), 2000, The Theory of Monetary Aggregation, North Holland, Amsterdam, chapter 17, pp. 360-388.

Belongia, M., 1996, “Measurement Matters: Recent Results from Monetary Economics Reexamined,” Journal of Political Economy, v. 104, No. 5, 1065-1083.

Belongia, M. and J. Binner (eds), 2000, Divisia Monetary Aggregates: Theory and Practice. Basingstoke: Palgrave.

Belongia, M. and P. Ireland, 2006, “The Own-Price of Money and the Channels of Monetary Transmission,” Journal of Money Credit and Banking, 38, No. 2, 429-445.

Brock, W. A., W. D. Dechert, J. A. Schenkman, and B. LeBaron, “A Test for Independence Based on the Correlation Dimension,” Econometric Reviews, 15(3), 1996, 197-235.

Bry, G., and C. Boschan, 1971, Cyclical Analysis of Times Series: Selected Procedures and Computer Programs, (New York: National Bureau of Economic Research).

Chauvet, M., 1998, “An Econometric Characterization of Business Cycle Dynamics with Factor Structure and Regime Switches," International Economic Review, Vol. 39, No. 4, November, 969-96.

Chauvet, M., 2001, “A Monthly Indicator of Brazilian GDP,” in Brazilian Review of Econometrics Vol. 21, No. 1.

Chrystal, A. and MacDonald, R. 1994. Empirical evidence on the recent behaviour and usefulness of simple-sum and weighted measures of the money stock. Federal Reserve Bank of St. Louis Review 76, 73-109.

Diewert, W. 1976. Exact and superlative index numbers. Journal of Econometrics 4, 115-45.

Divisia, F. 1925. L'Indice monétaire et la théorie de la monnaie. Revue d'Economie Politique 39, 980-1008. 
Feenstra, R. C., 1986, "Functionial Equivalence between Liquidity Costs and the Utility of Money,” Journal of Monetary Economics 17, 271-291.

Fischer, Stanley, 1974, “Money and the Production Function,” Economic Inquiry 12, 517-533.

Friedman, Milton and Anna Schwartz, 1970, Monetary Statistics of the United States: Estimation, Sources, Methods, and Data, New York, Columbia University Press.

Harrison, P. J. and C. F. Stevens, 1976, “Bayesian Forecasting,” Journal of the Royal Statistical Society Series B 38, 205-247.

Haywood, E., 1973, “The Deviation Cycle: A New Index of the Australian Business Cycle, 1950-1973,” Australian Economic Review, $4^{\text {th }}$ Quarter, 31-39.

Hicks, J. R., 1946, “Value and Capital,” Oxford: Clarendon Press.

Jones, B., Dutkowsky, D. and Elger, T. 2005. Sweep programs and optimal monetary aggregation. Journal of Banking and Finance 29, 483-508.

Kim, C.J. and C. Nelson, 1998, "State-Space Models with Regime-Switching: Classical and Gibbs-Sampling Approaches with Applications,” The MIT Press.

Lucas, Robert E., 2000, “Inflation and Welfare,” Econometrica, vol 68, no. 62, March, pp. 247274.

Phlips, Louis and Frank Spinnewyn, 1982, "Rationality versus Myopia in Dynamic Demand Systems.” In Advances in Econometrics, R. L. Basmann and G. F. Rhodes (eds.), Greenwich, CT: JAI Press, 3-33.

Poterba, J. and J. Rotemberg, 1987, "Money in the Utility Function: An Empirical Implementation.” In New Approaches to Monetary Economics, W. A. Barnett and K. J. Singleton (eds.), Cambridge: Cambridge University Press, 219-240.

Serletis, A. (ed.), 2006, “Money and the Economy,” World Scientific.

Schunk, D., 2001, “The Relative Forecasting Performance of the Divisia and Simple Sum Monetary Aggregates,” Journal of Money, Credit and Banking, 33, No. 2, 272-283. 
Table 1: Maximum Likelihood Estimates

\begin{tabular}{|c|c|c|c|}
\hline Parameters & M1 and MSI1 & M2 and MSI2 & M3 and MSI3 \\
\hline \multirow[t]{2}{*}{$\alpha_{0}$} & -0.226 & 0.621 & -0.767 \\
\hline & $(0.022)$ & (0.115) & (0.137) \\
\hline \multirow[t]{2}{*}{$\alpha_{1}$} & 0.636 & 0.731 & 0.949 \\
\hline & $(0.226)$ & (0.195) & $(0.141)$ \\
\hline \multirow[t]{2}{*}{$\Phi$} & 0.556 & 0.518 & 0.497 \\
\hline & $(0.070)$ & $(0.082)$ & $(0.071)$ \\
\hline \multirow[t]{2}{*}{$d_{M}$} & 0.431 & 0.976 & 0.962 \\
\hline & $(0.084)$ & $(0.020)$ & $(0.039)$ \\
\hline \multirow[t]{2}{*}{$d_{M S I}$} & 0.979 & 0.589 & 0.603 \\
\hline & $(0.010)$ & $(0.095)$ & $(0.075)$ \\
\hline \multirow[t]{2}{*}{$\sigma^{2}$} & 0.511 & 0.254 & 0.157 \\
\hline & $(0.056)$ & $(0.038)$ & $(0.026)$ \\
\hline \multirow[t]{2}{*}{$\sigma_{M}^{2}$} & 0.030 & 0.006 & 0.005 \\
\hline & $(0.003)$ & $(0.003)$ & $(0.002)$ \\
\hline \multirow[t]{2}{*}{$\sigma_{M S I}^{2}$} & 1.099 & 0.047 & 0.093 \\
\hline & $(0.018)$ & $(0.007)$ & $(0.011)$ \\
\hline \multirow[t]{2}{*}{$\lambda_{\mathbf{M}}$} & 1.099 & 0.977 & 1.172 \\
\hline & $(0.018)$ & $(0.034)$ & $(0.054)$ \\
\hline \multirow[t]{2}{*}{$p_{00}^{\alpha}$} & 0.987 & 0.970 & 0.857 \\
\hline & $(0.016)$ & $(0.031)$ & $(0.076)$ \\
\hline \multirow{2}{*}{$p_{11}^{\alpha}$} & 0.941 & 0.795 & 0.967 \\
\hline & $(0.059)$ & $(0.150)$ & $(0.022)$ \\
\hline \multirow[t]{2}{*}{$p_{00}^{\beta}$} & 0.560 & 0.633 & 0.992 \\
\hline & $(0.209)$ & $(0.144)$ & $(0.009)$ \\
\hline \multirow{2}{*}{$p_{11}^{\beta}$} & 0.967 & 0.977 & 0.976 \\
\hline & $(0.019)$ & $(0.011)$ & $(0.021)$ \\
\hline \multirow[t]{2}{*}{$p_{00}^{\delta}$} & 0.954 & 0.681 & 0.679 \\
\hline & $(0.019)$ & (0.138) & $(0.136)$ \\
\hline \multirow[t]{2}{*}{$p_{11}^{\delta}$} & 0.701 & 0.971 & 0.972 \\
\hline & $(0.137)$ & $(0.014)$ & $(0.014)$ \\
\hline \multirow[t]{2}{*}{$\beta_{0}$} & -0.322 & -0.549 & -0.040 \\
\hline & $(0.063)$ & (0.059) & $(0.010)$ \\
\hline \multirow[t]{2}{*}{$\beta_{l}$} & 0.024 & 0.009 & 0.262 \\
\hline & $\begin{array}{l}(0.012) \\
-0.018\end{array}$ & $\begin{array}{l}(0.002) \\
-0703\end{array}$ & $\begin{array}{l}(0.015) \\
-0.857\end{array}$ \\
\hline$\delta_{0}$ & $\begin{array}{l}-0.018 \\
(0.010)\end{array}$ & $\begin{array}{l}-0.703 \\
(0.433)\end{array}$ & $\begin{array}{l}-0.03 / \\
(0.086)\end{array}$ \\
\hline \multirow[t]{2}{*}{$\delta_{1}$} & 0.096 & 0.008 & 0.051 \\
\hline & $(0.020)$ & $(0.003)$ & $(0.020)$ \\
\hline \multirow[t]{2}{*}{$\tau$} & 0.002 & 0.002 & 0.004 \\
\hline & $(0.001)$ & $(0.001)$ & $(0.0007)$ \\
\hline $\log \mathrm{L}(\theta)$ & -88.404 & $\begin{array}{l}-68.893 \\
\end{array}$ & -77.295 \\
\hline
\end{tabular}

Asymptotic standard errors in parentheses. 
Table 2: Correlation Coefficients between Monetary Indexes and Dynamic Factors

\begin{tabular}{|l|l|l|l|l|l|l|}
\hline Parameters & $\mathbf{M}_{\mathbf{1}}$ & MSI $_{\mathbf{1}}$ & $\mathbf{M}_{\mathbf{2}}$ & $\mathbf{M S I}_{\mathbf{2}}$ & $\mathbf{M}_{\mathbf{3}}$ & $\mathbf{M S I}_{\mathbf{3}}$ \\
\hline $\mathbf{D F M}_{\mathbf{1}}$ & 0.988 & 0.998 & 0.337 & 0.423 & 0.150 & 0.265 \\
$\mathbf{D F M}_{\mathbf{2}}$ & 0.354 & 0.339 & 0.947 & 0.963 & 0.767 & 0.883 \\
$\mathbf{D F M}_{\mathbf{3}}$ & 0.120 & 0.128 & 0.793 & 0.732 & 0.987 & 0.902 \\
$\mathbf{M}_{\mathbf{1}}$ & 1 & 0.984 & 0.354 & 0.429 & 0.139 & 0.260 \\
$\mathbf{M S I}_{\mathbf{1}}$ & 0.984 & 1 & 0.332 & 0.418 & 0.151 & 0.261 \\
$\mathbf{M}_{2}$ & 0.354 & 0.332 & 1 & 0.894 & 0.802 & 0.806 \\
$\mathbf{M S I}_{\mathbf{2}}$ & 0.429 & 0.418 & 0.894 & 1 & 0.693 & 0.904 \\
$\mathbf{M}_{3}$ & 0.139 & 0.151 & 0.802 & 0.693 & 1 & 0.858 \\
$\mathbf{M S I}_{\mathbf{3}}$ & 0.260 & 0.261 & 0.806 & 0.904 & 0.858 & 1 \\
\hline
\end{tabular}


Figure 1a: Smoothed Inflation (-), Inflation (-), High Inflation Phases (-), and NBER Recessions (Shaded Area)

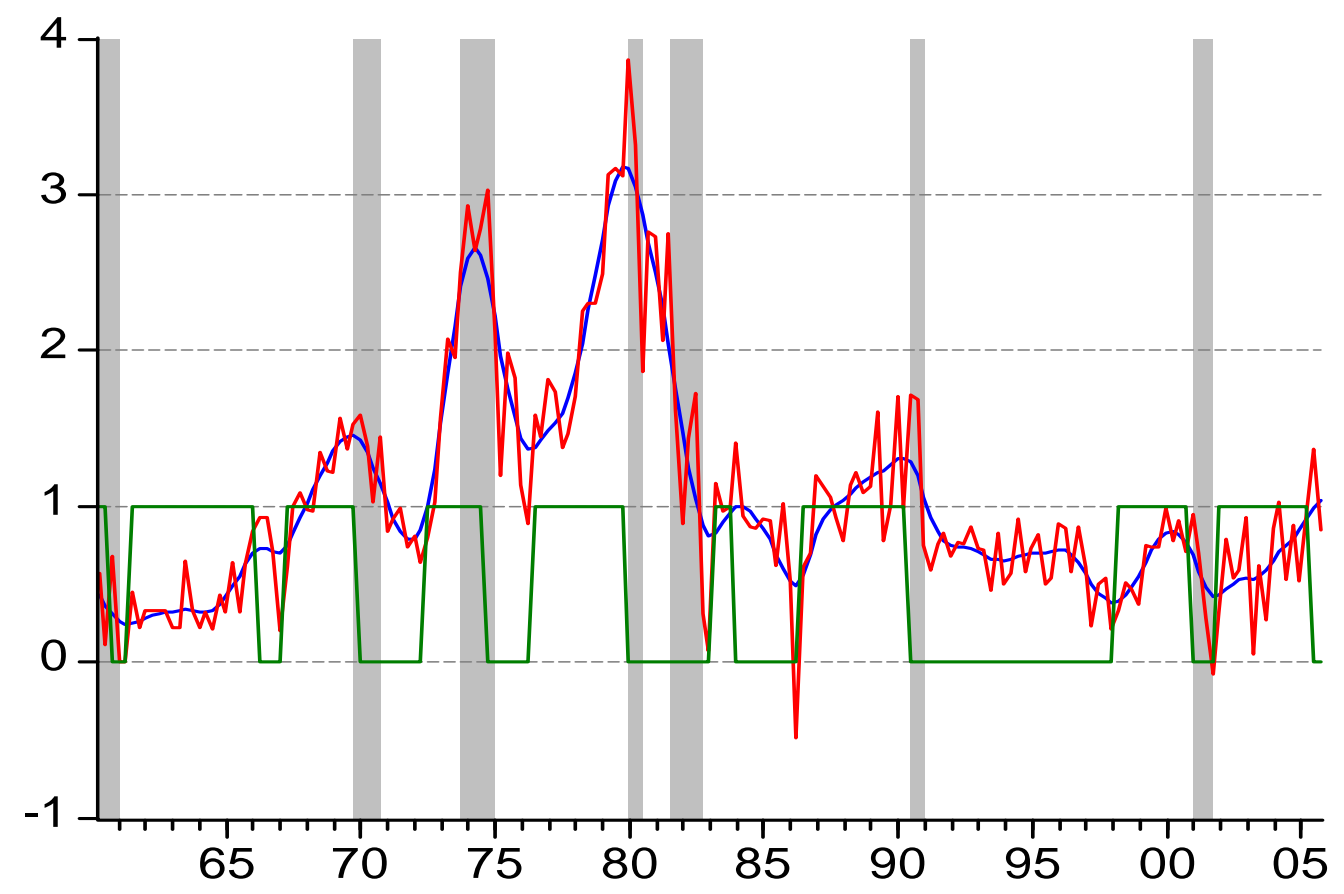

Figure 1b: Interest Rates (-), High Interest Rates Phases (-), and NBER Recessions (Shaded Area)

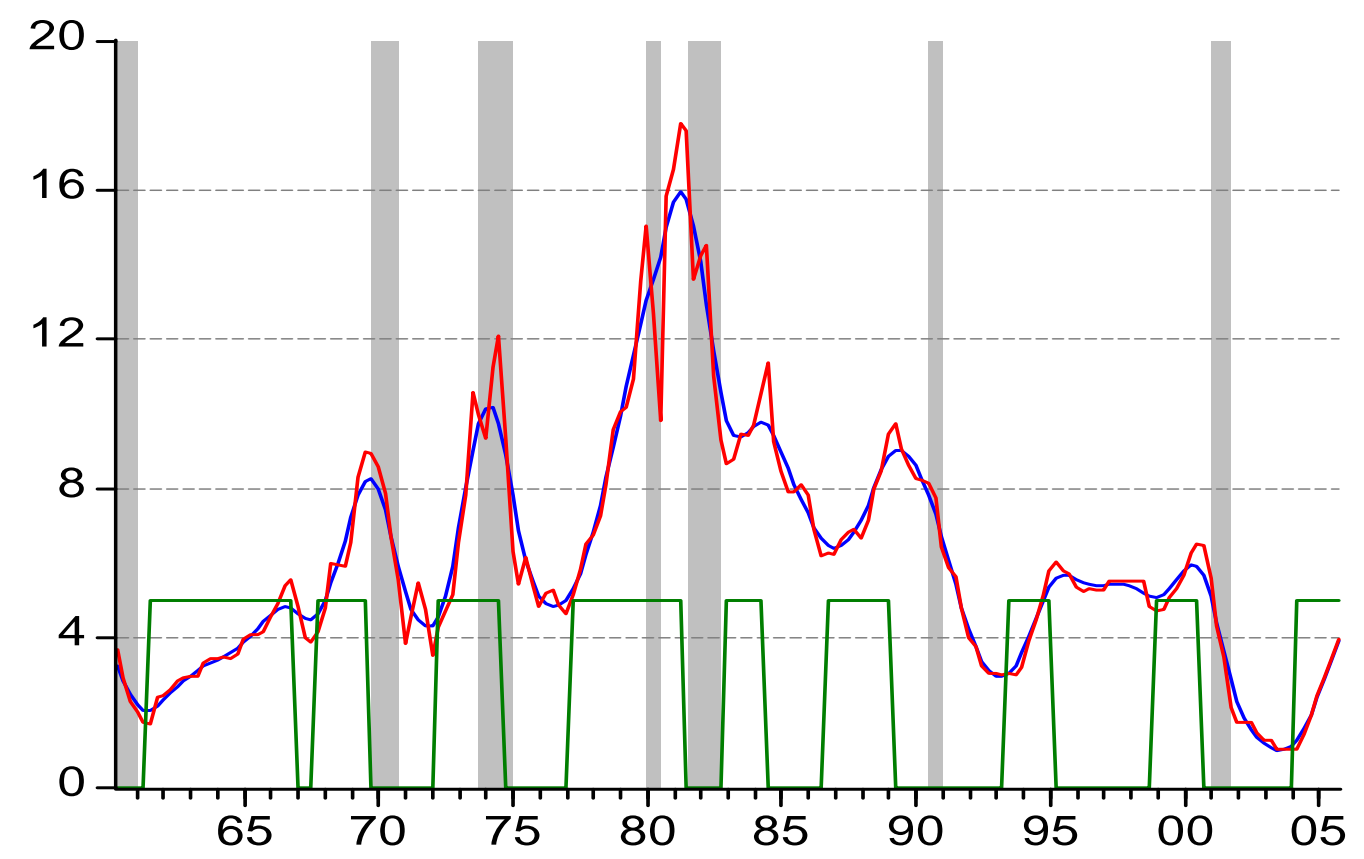


Figure 1c: Dynamic Factors from the Pairs M1-MSI1 Growth (-), M2-MSI2 Growth (-) and M3-MSI3 (-) Growth, High Interest Rate Phases (-), High Inflation Phases (-), and NBER Recessions (Shaded Area)

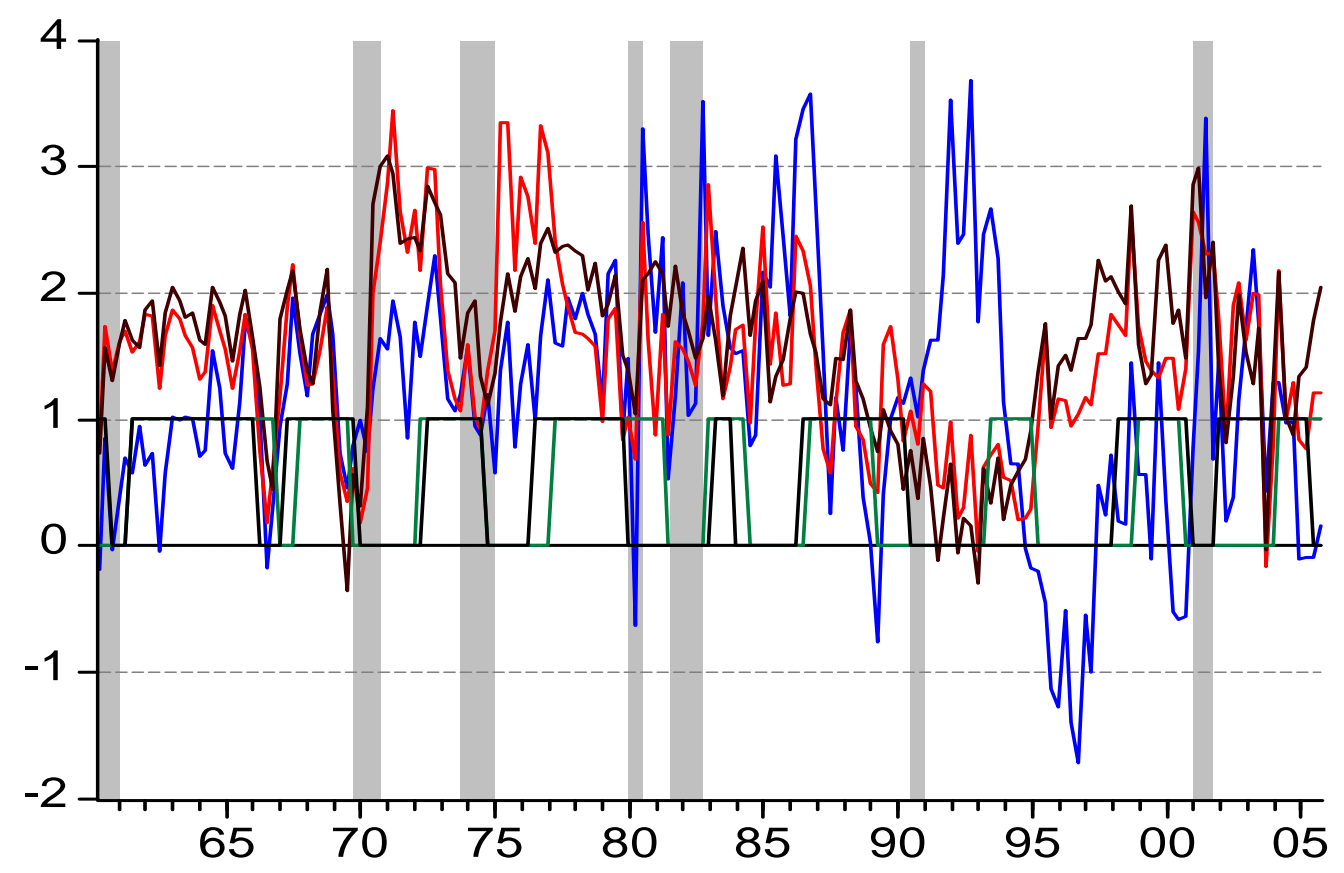

Figure 2a: Dynamic Factor ( - ) and Probabilities of High Monetary Growth Based on M1 and MSI1 ( - ), and NBER Recessions (Shaded Area)

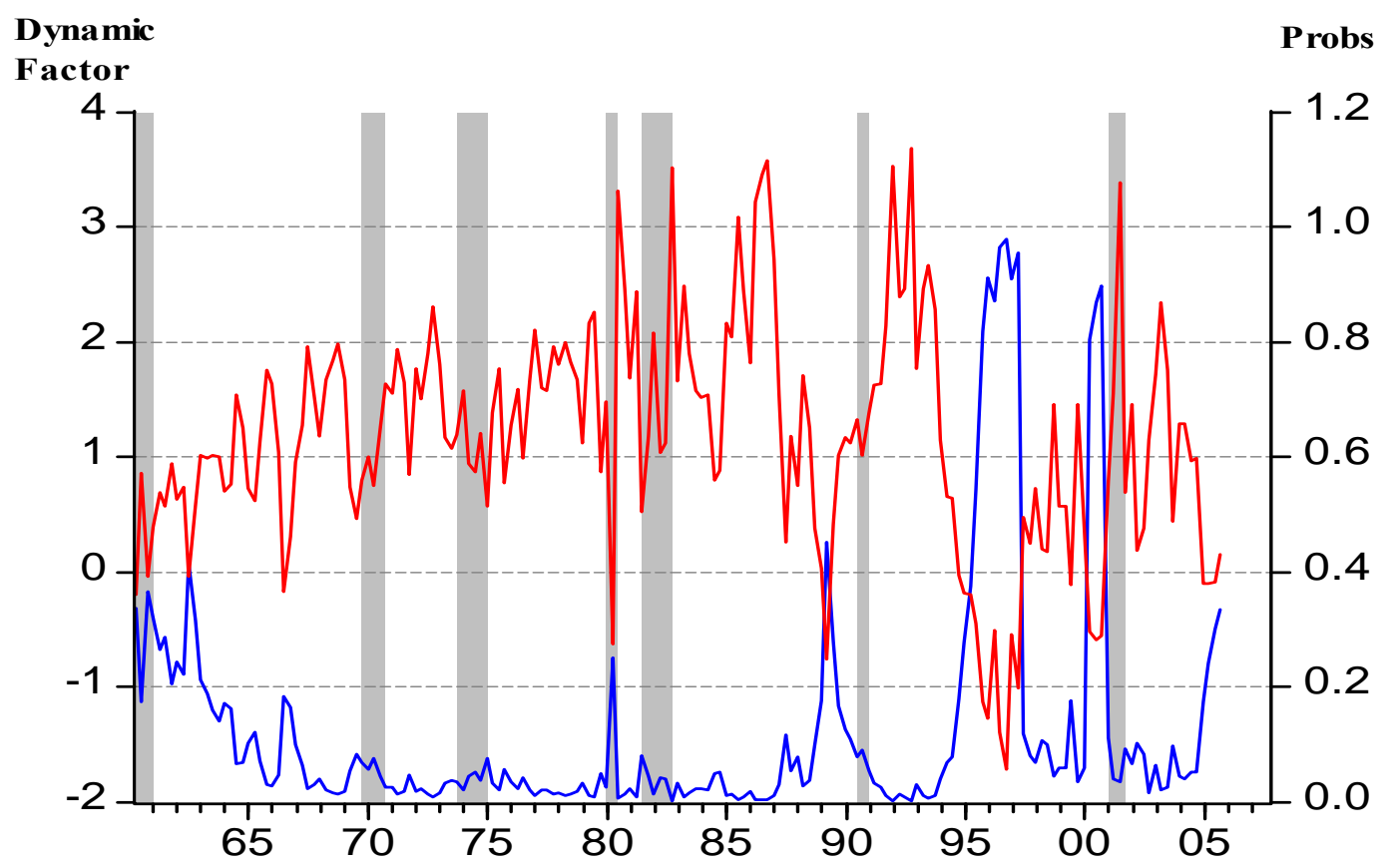


Figure 2b: Dynamic Factor (-), Rate of Growth of M1 (-) and MSI1 (-), and NBER Recessions (Shaded Area)

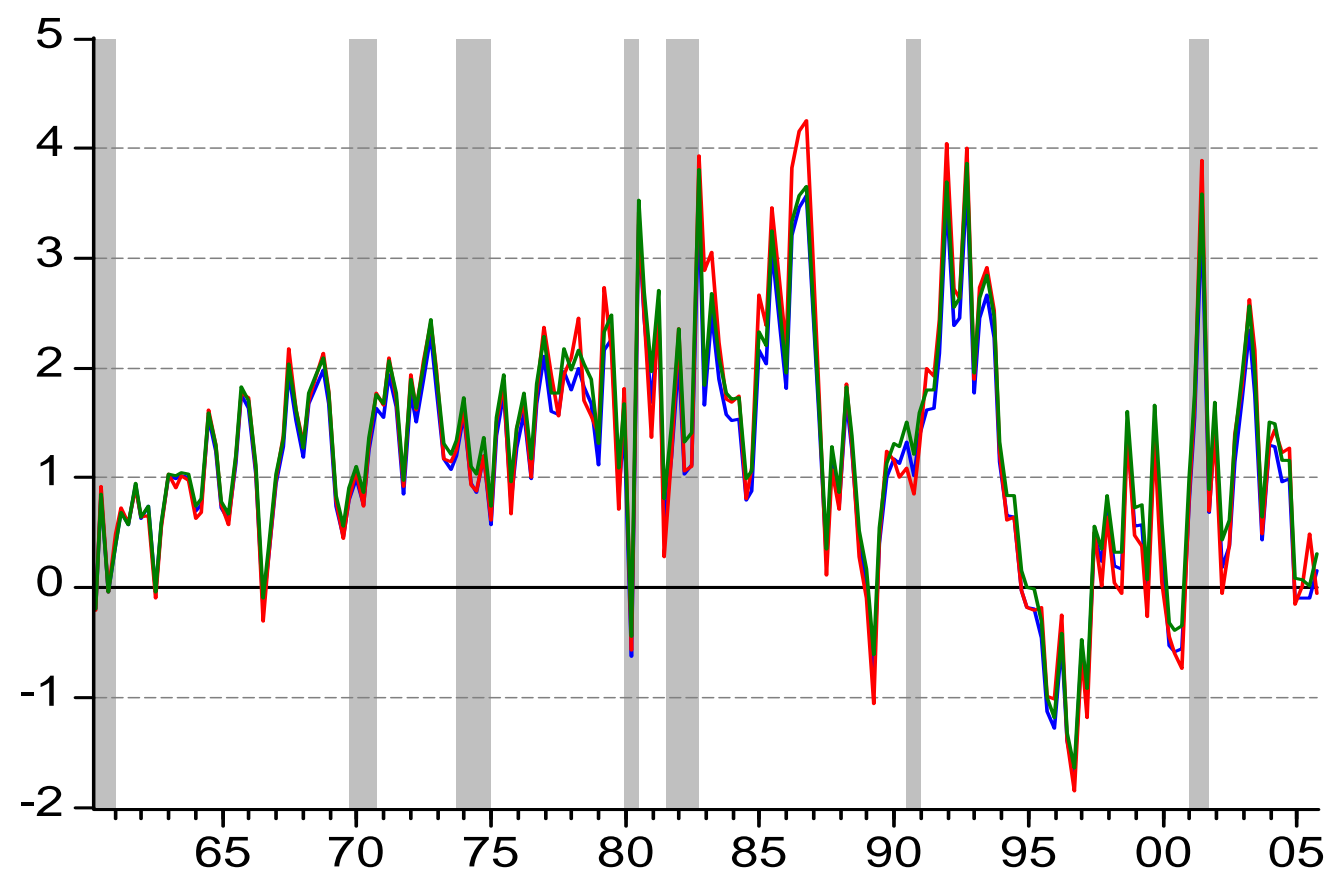

Figure 2c: Idiosyncratic Terms for M1 (-) and MSI1 Growth (-), High Interest Rate Phases (-), High Inflation Phases (-), and NBER Recessions (Shaded Area)

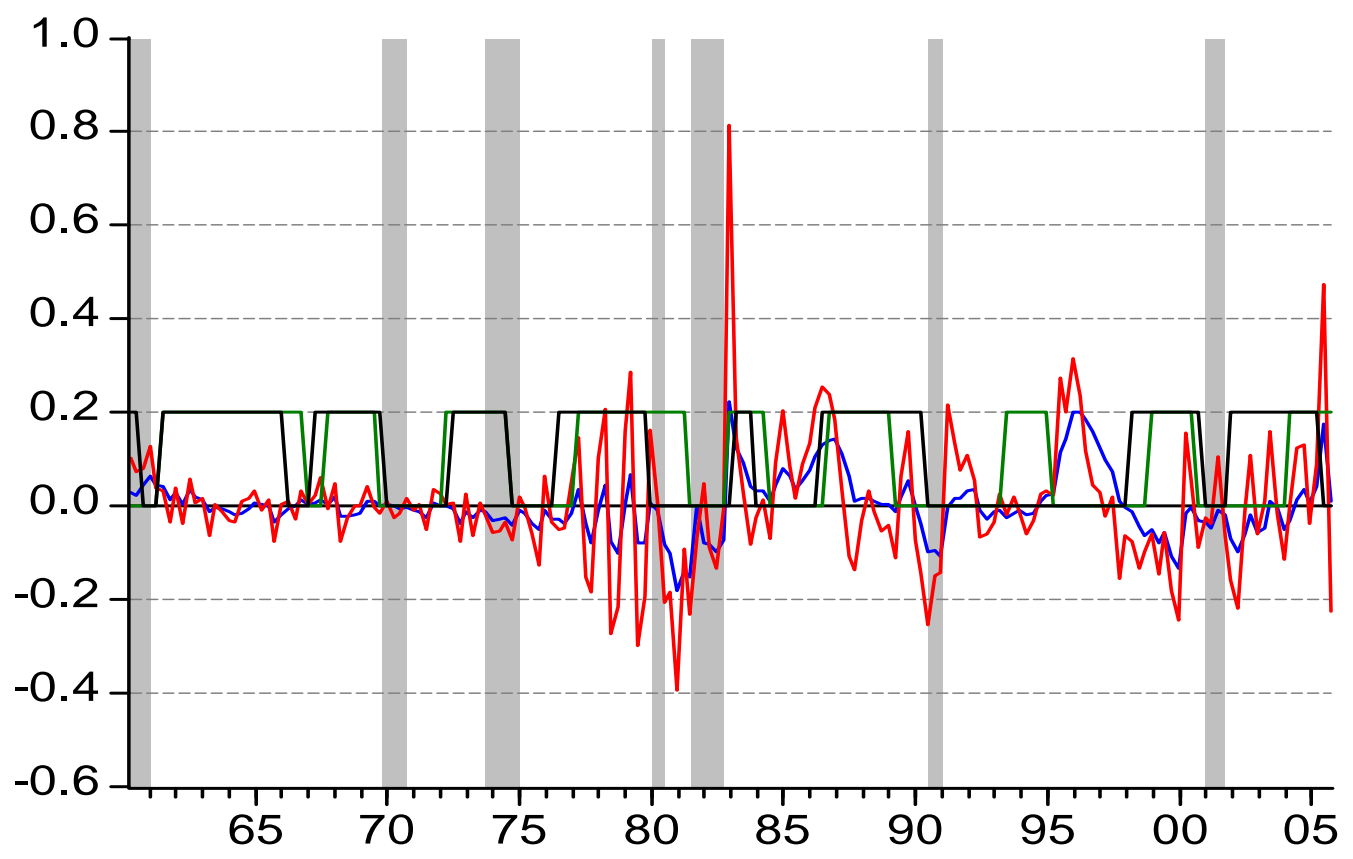


Figure 2d: Difference between Idiosyncratic Terms for M1 and MSI1 Growth without (一), and with Dummy (-), High Interest Rate Phases (-), High Inflation Phases $(-)$, and NBER Recessions (Shaded Area)

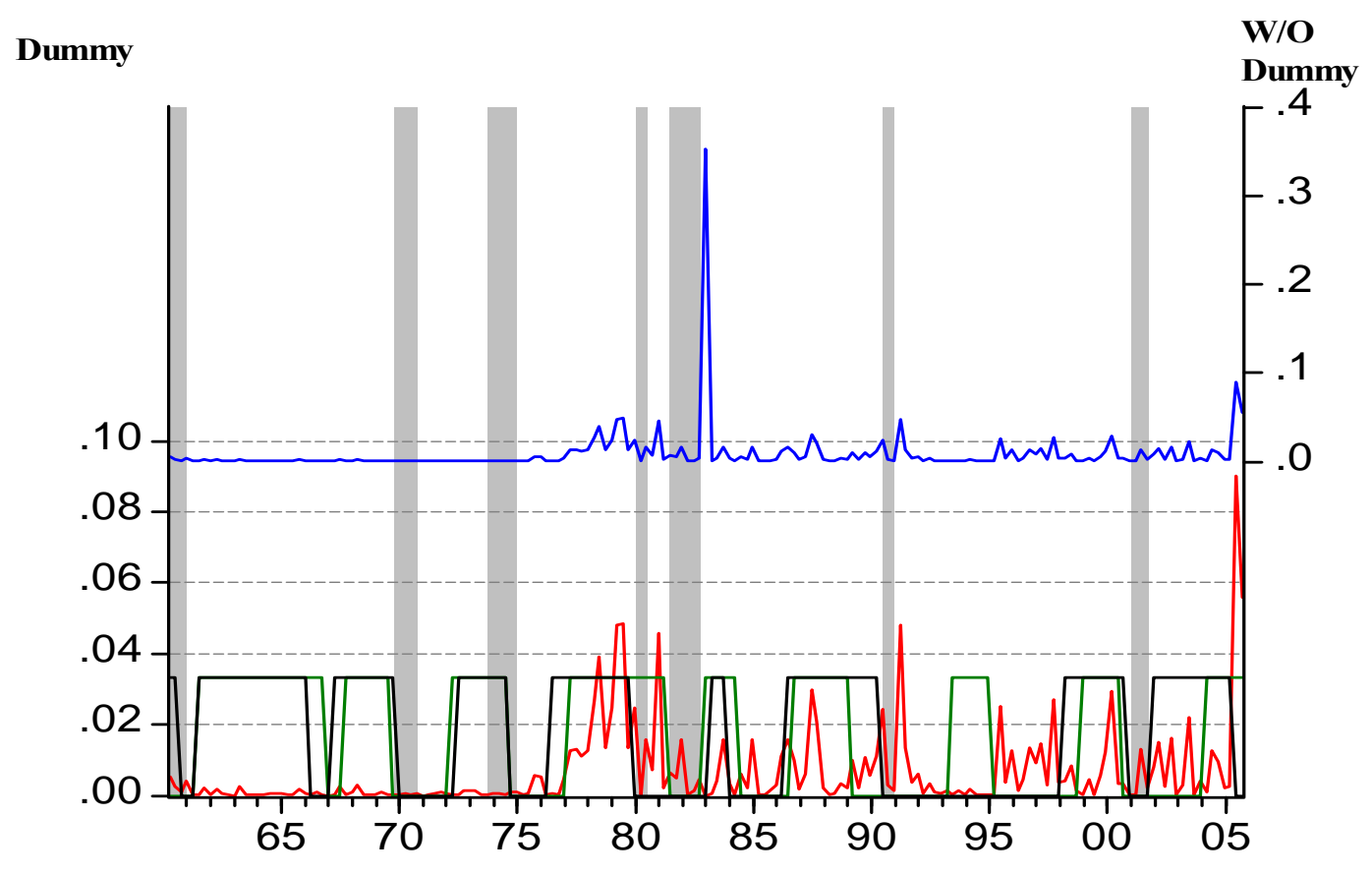

Figure 2e: Measurement Errors for M1 (-) and MSI1 Growth (-), High Interest Rate Phases (-), High Inflation Phases (-), and NBER Recessions (Shaded Area)

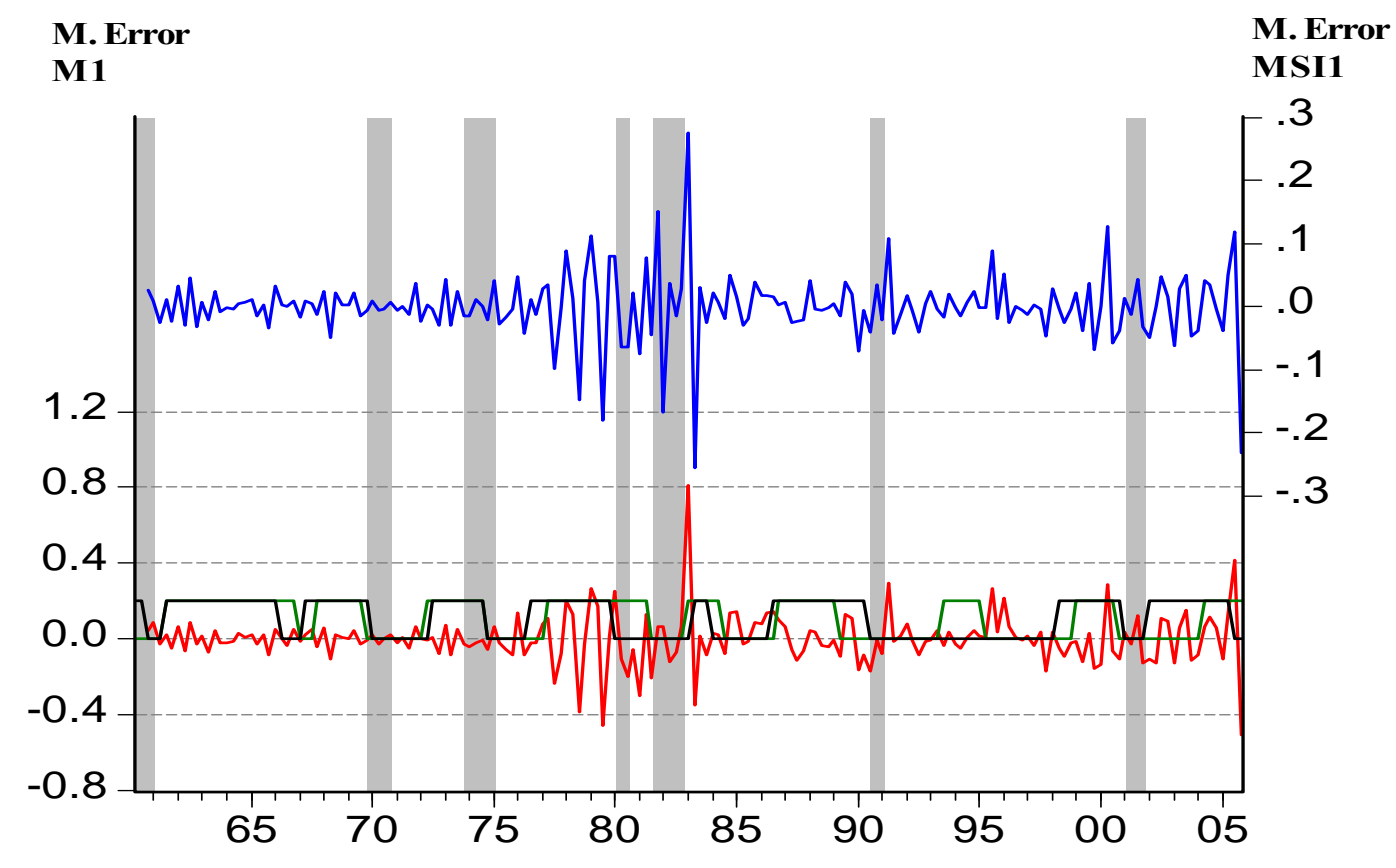


Figure 2f: Difference between Measurement Errors for M1 and MSI1 Growth without (-), and with Dummy (-), High Interest Rate Phases (-), High Inflation Phases (-), and NBER Recessions (Shaded Area)

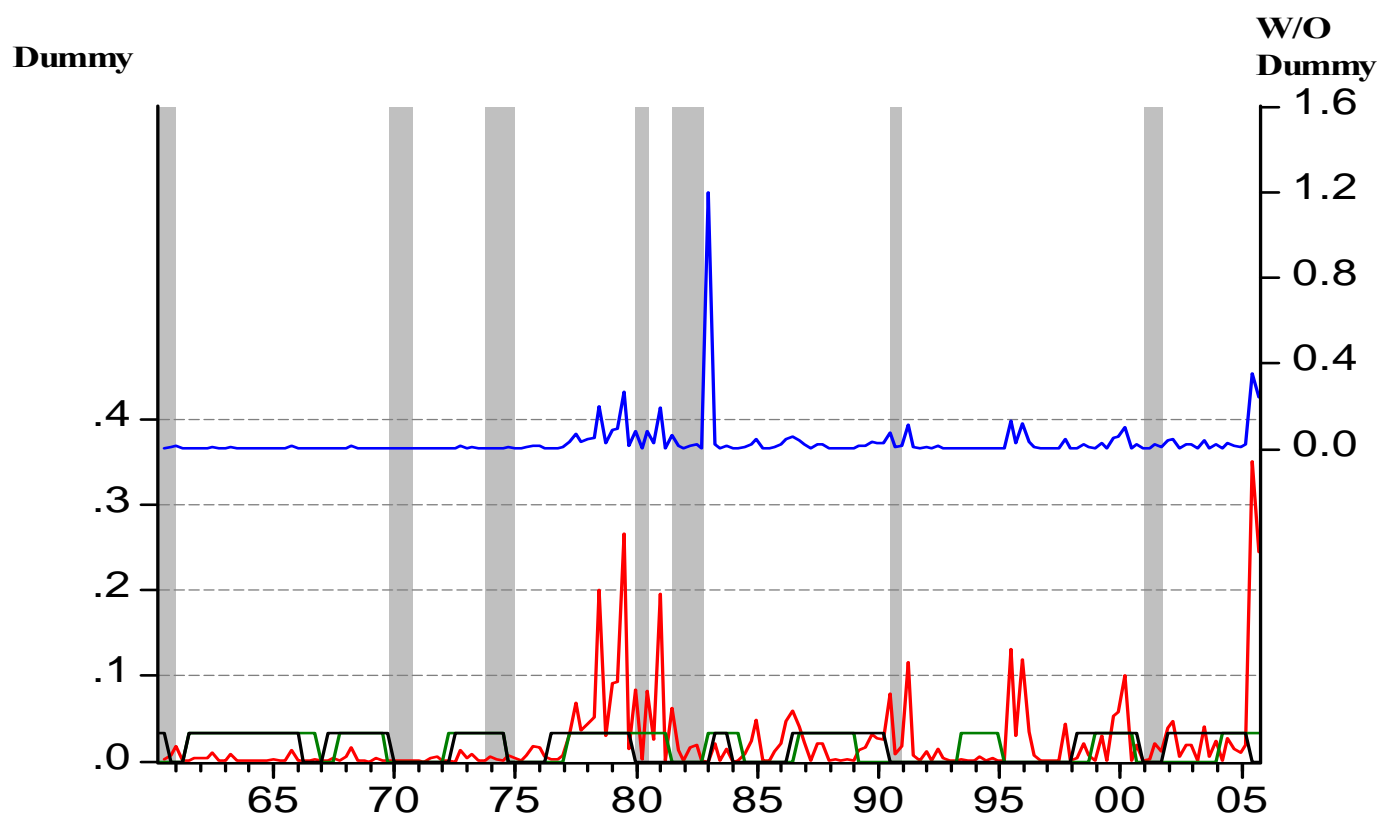

Figure 3a: Dynamic Factor ( - ) and Probabilities of High Monetary Growth Based on M2 and MSI2 (-), and NBER Recessions (Shaded Area)

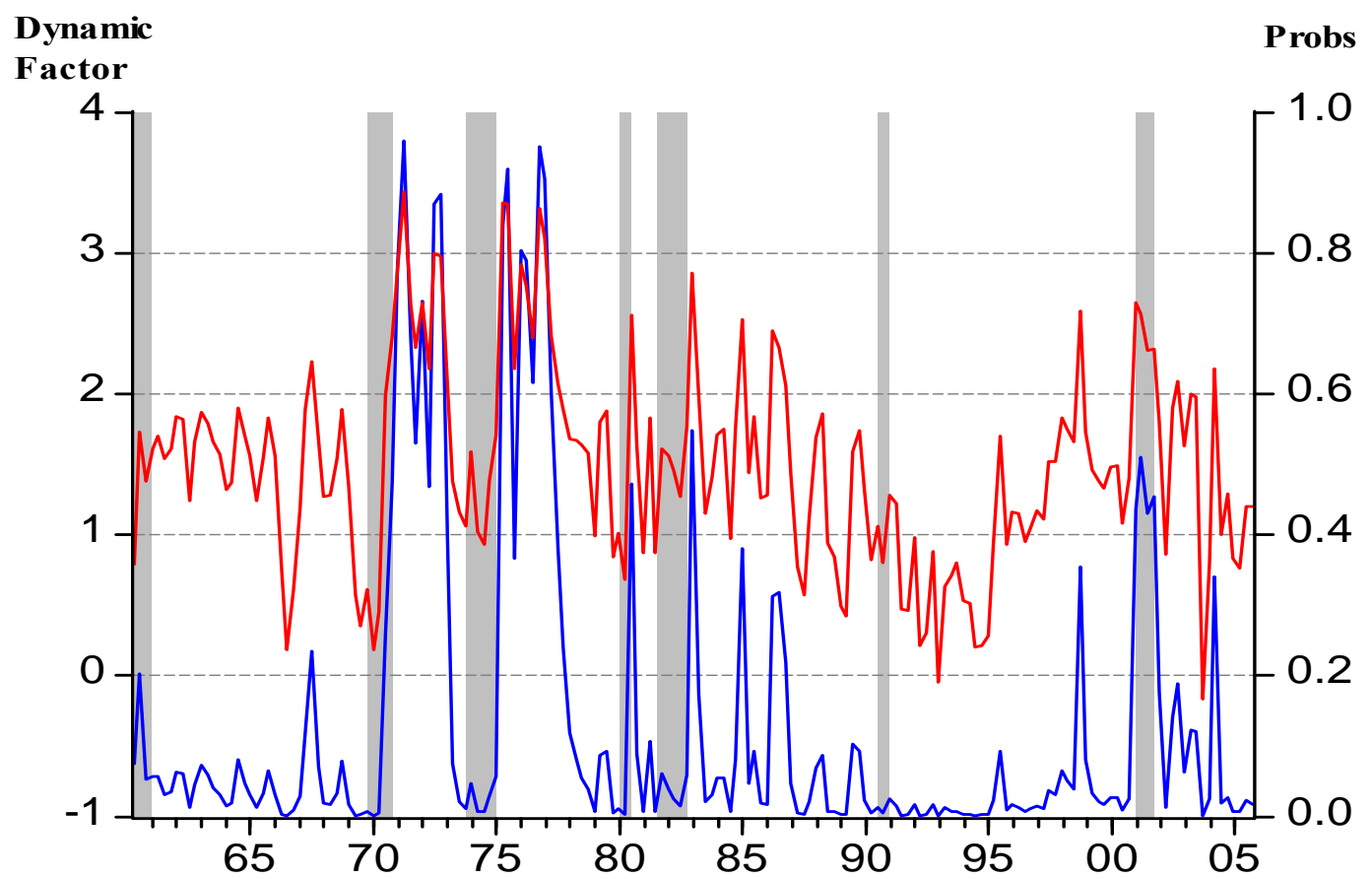


Figure 3b: Dynamic Factor (-), Rate of Growth of M2 (-) and MSI2 (-), and NBER Recessions (Shaded Area)

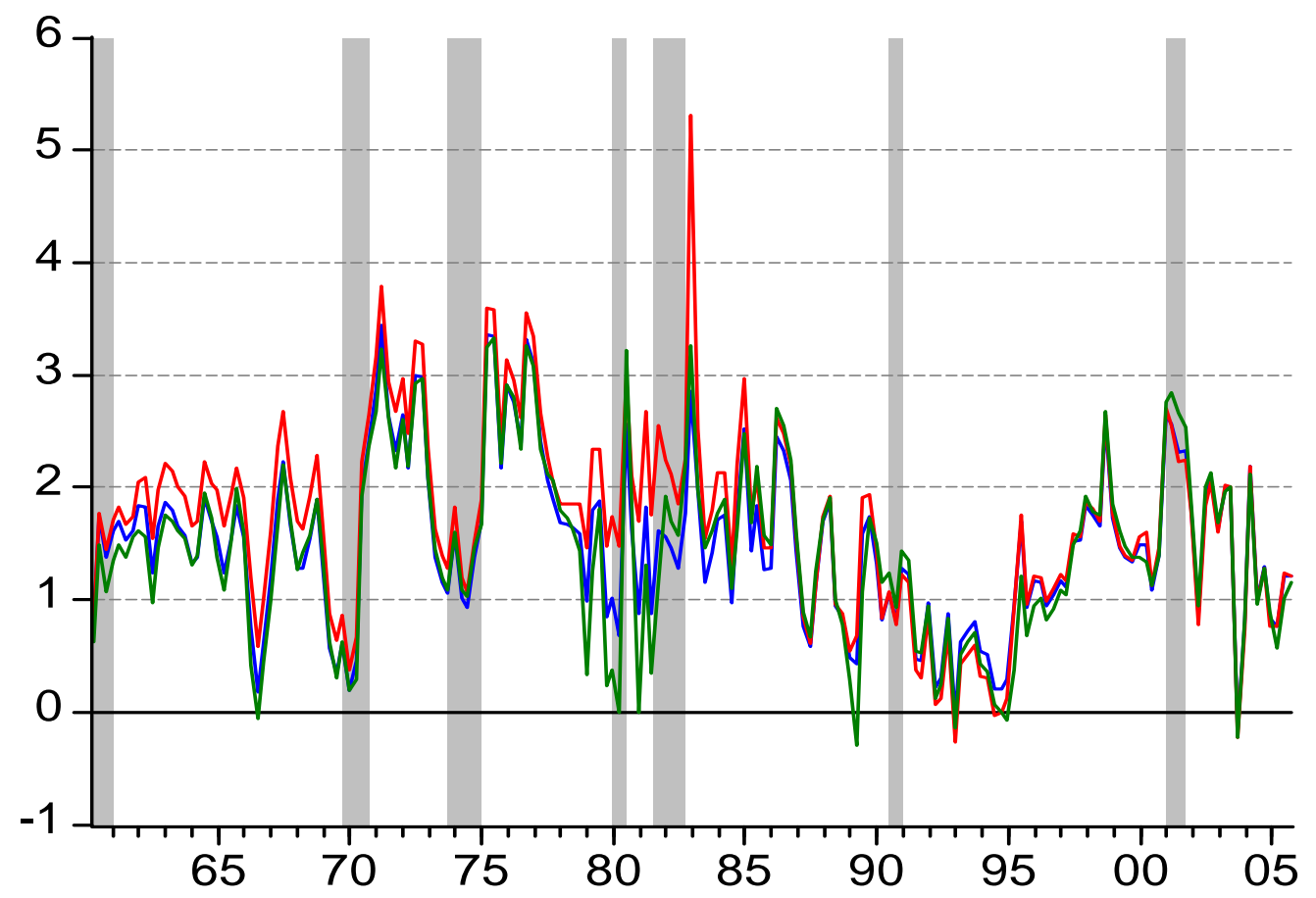

Figure 3c: Idiosyncratic Terms for M2 (-) and MSI2 Growth (-), High Interest Rate Phases (-), High Inflation Phases (-), and NBER Recessions (Shaded Area)

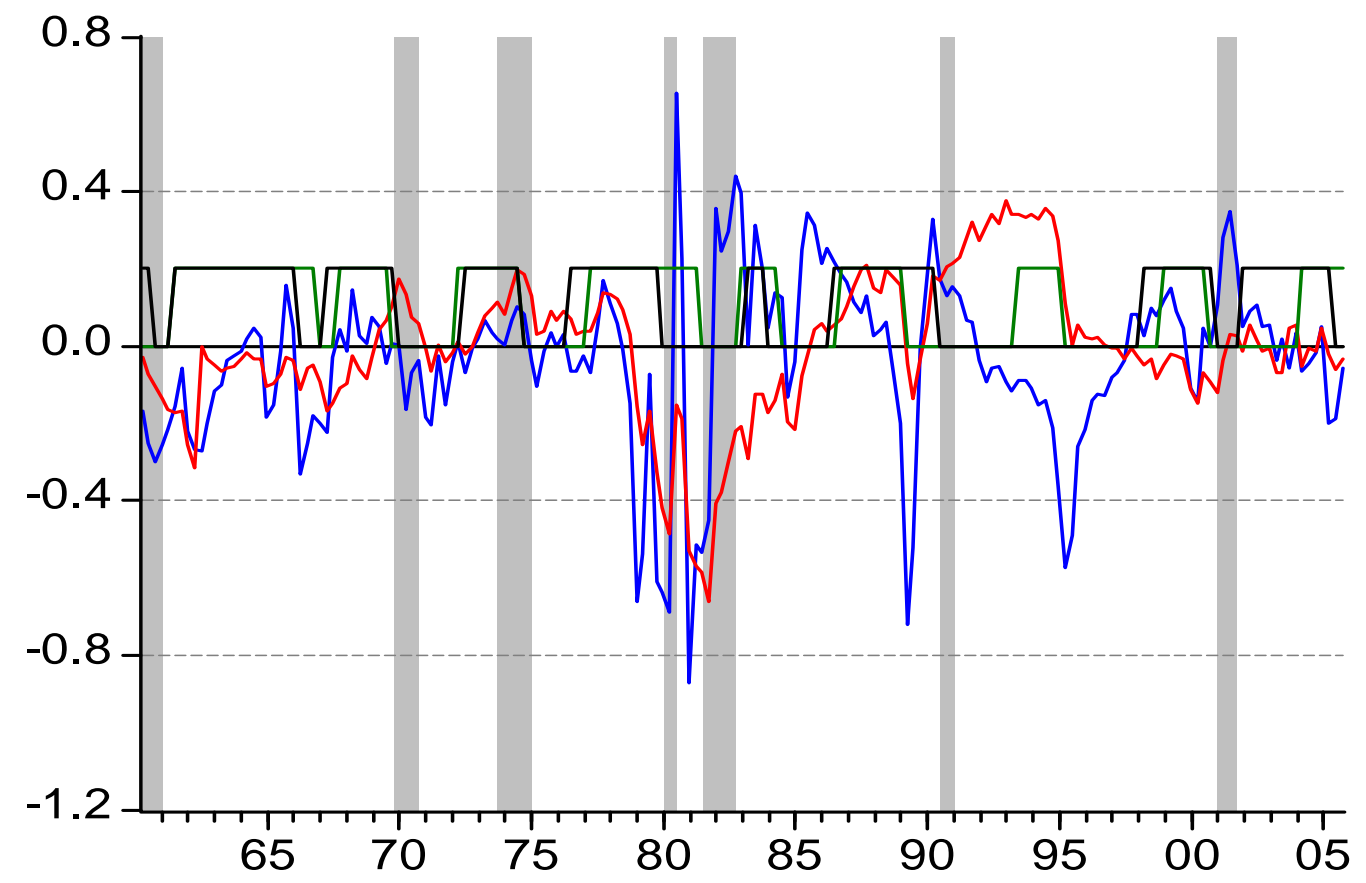


Figure 3d: Difference between Idiosyncratic Terms for M2 and MSI2 Growth (-), High Interest Rate Phases (-), High Inflation Phases (-), and NBER Recessions (Shaded Area)

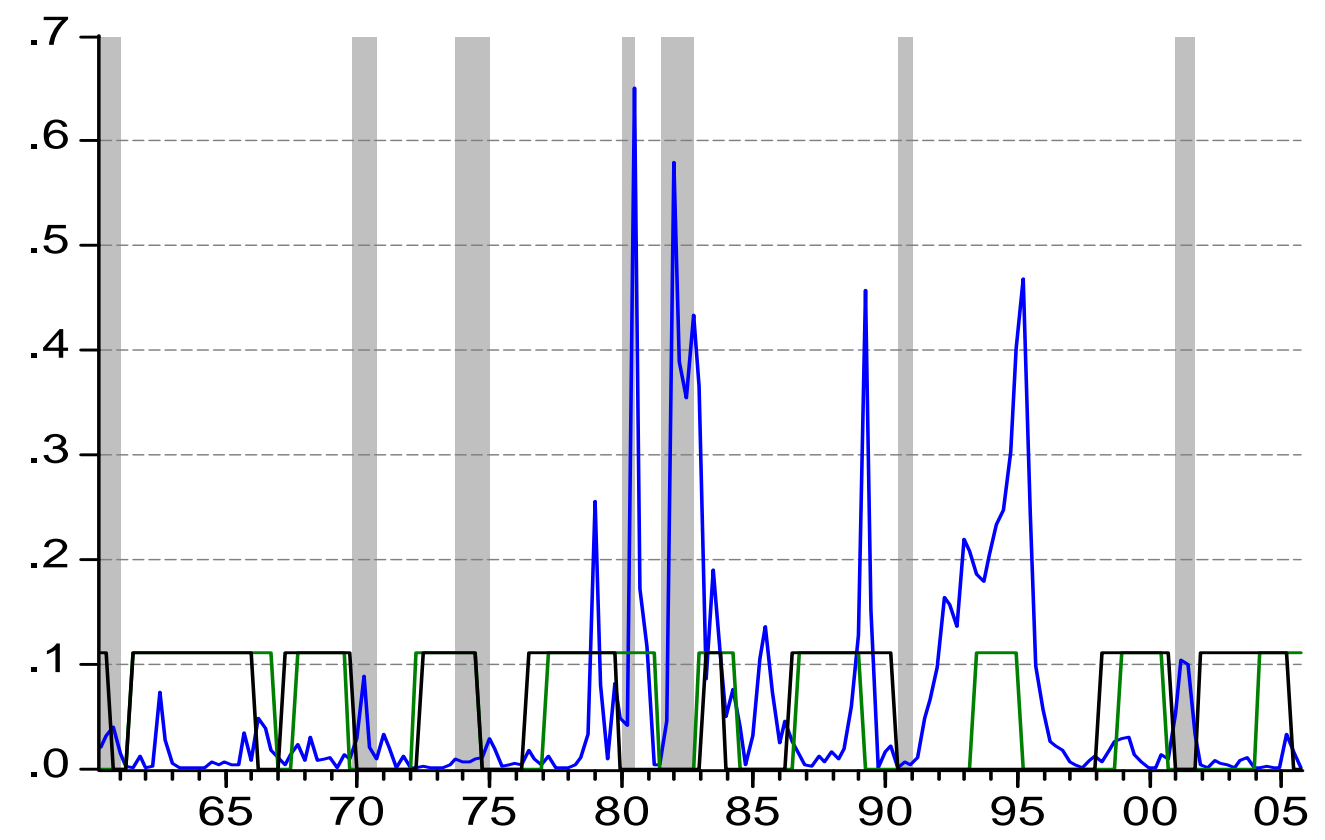

Figure 3f: Difference between Measurement Errors for M2 and MSI2 Growth (-), High Interest Rate Phases (-), High Inflation Phases (-), and NBER Recessions (Shaded Area)

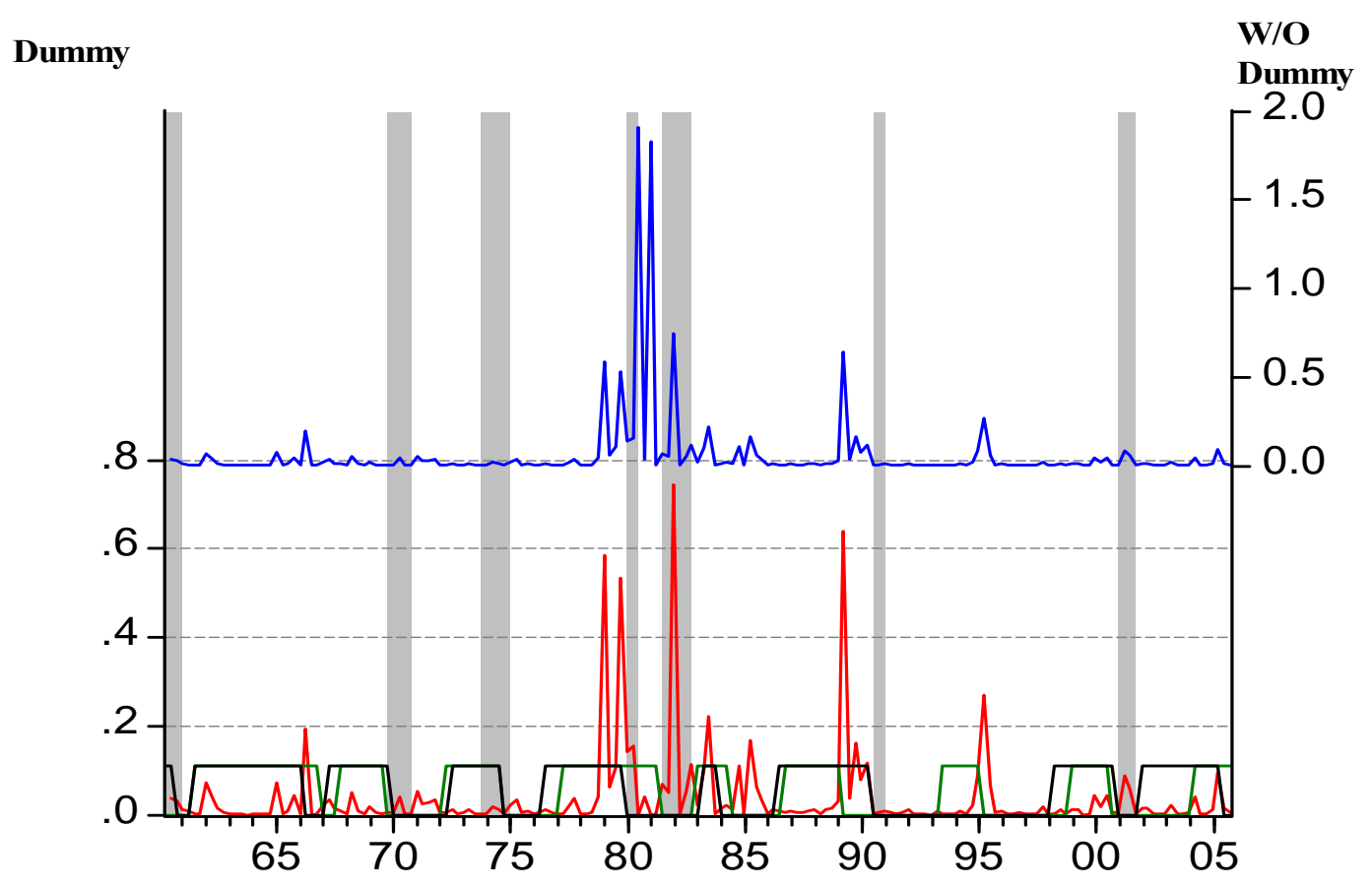


Figure 4a: Dynamic Factor (-) and Probabilities of Low Monetary Growth Based on M3 and MSI3 (-), and NBER Recessions (Shaded Area)

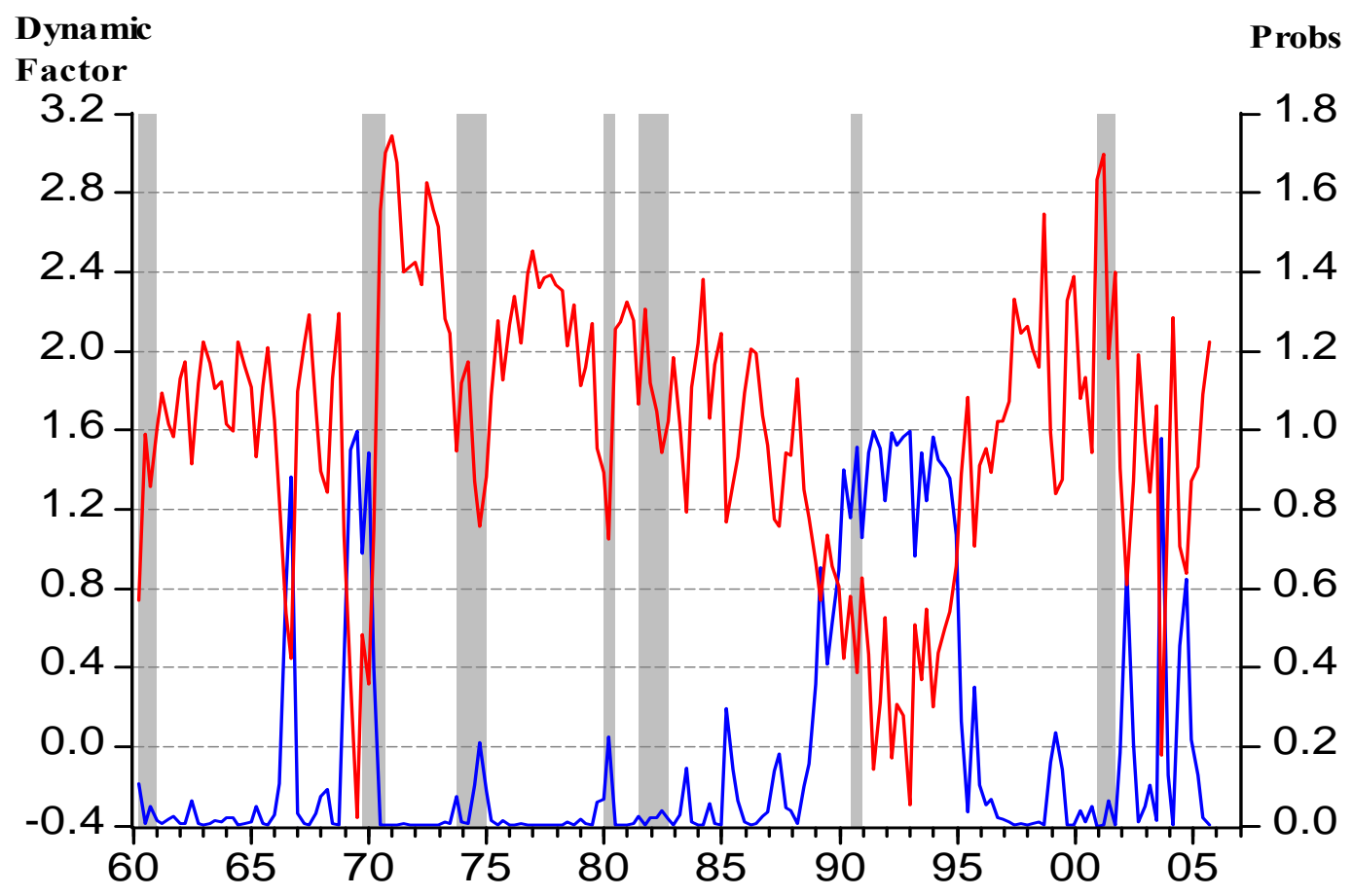

Figure 4b: Dynamic Factor (-), Rate of Growth of M3 (-) and MSI3 (-), and NBER Recessions (Shaded Area)

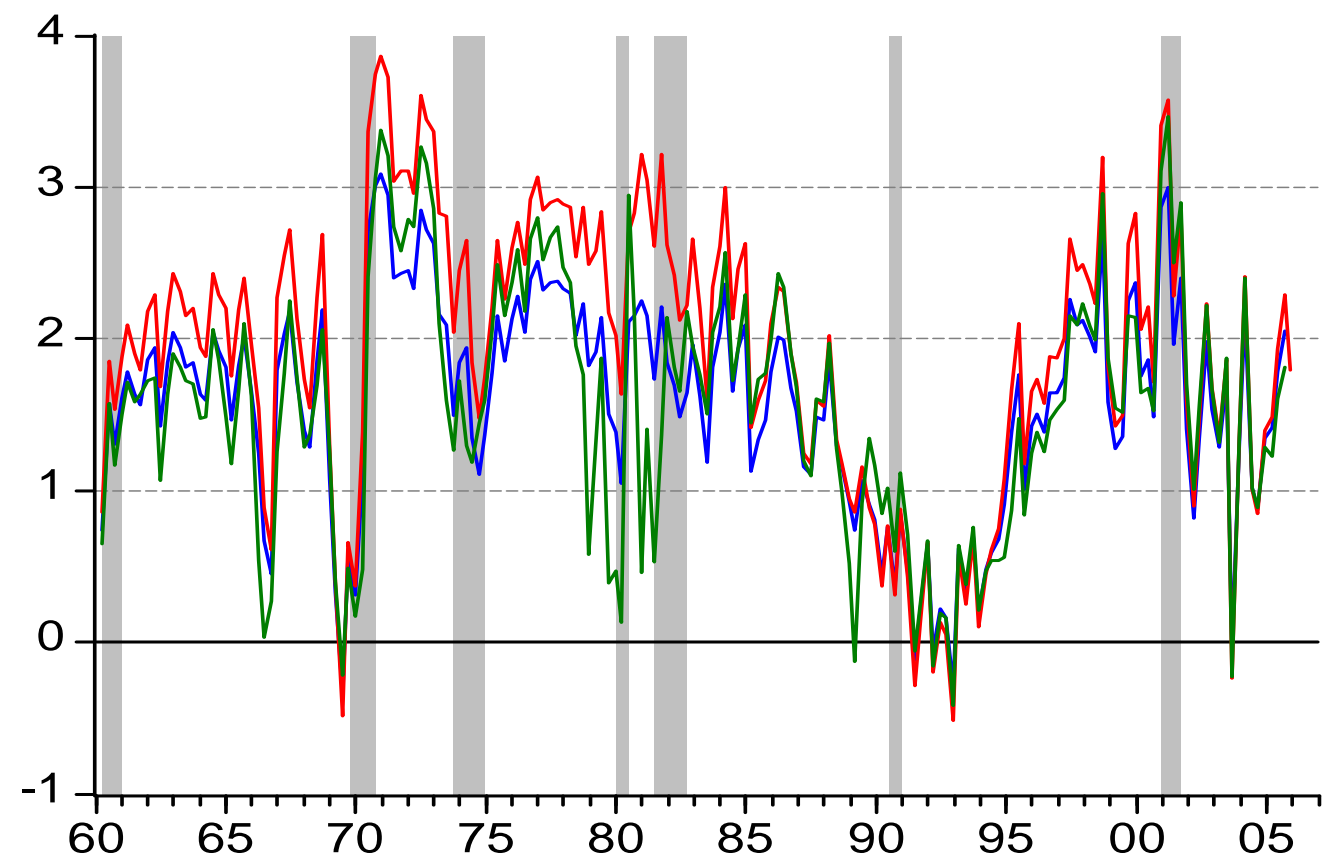


Figure 4c: Idiosyncratic Terms for M3 (-) and MSI3 Growth (-), High Interest Rate Phases (-), High Inflation Phases (-), and NBER Recessions (Shaded Area)

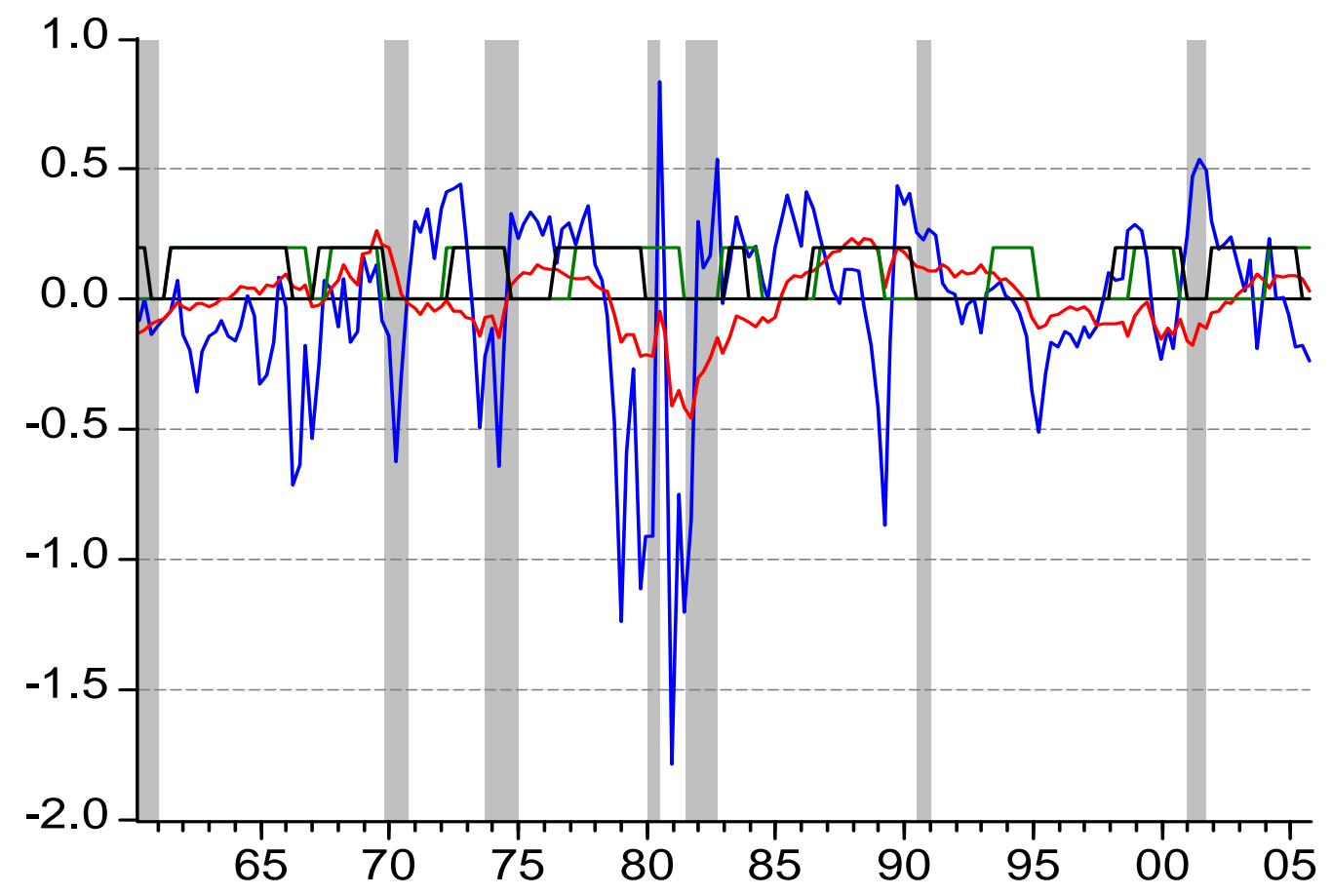

Figure 4d: Difference between Idiosyncratic Terms for M3 and MSI3 Growth Without $(-)$, and With Dummy (-), High Interest Rate Phases (-), High Inflation Phases (-), and NBER Recessions (Shaded Area)

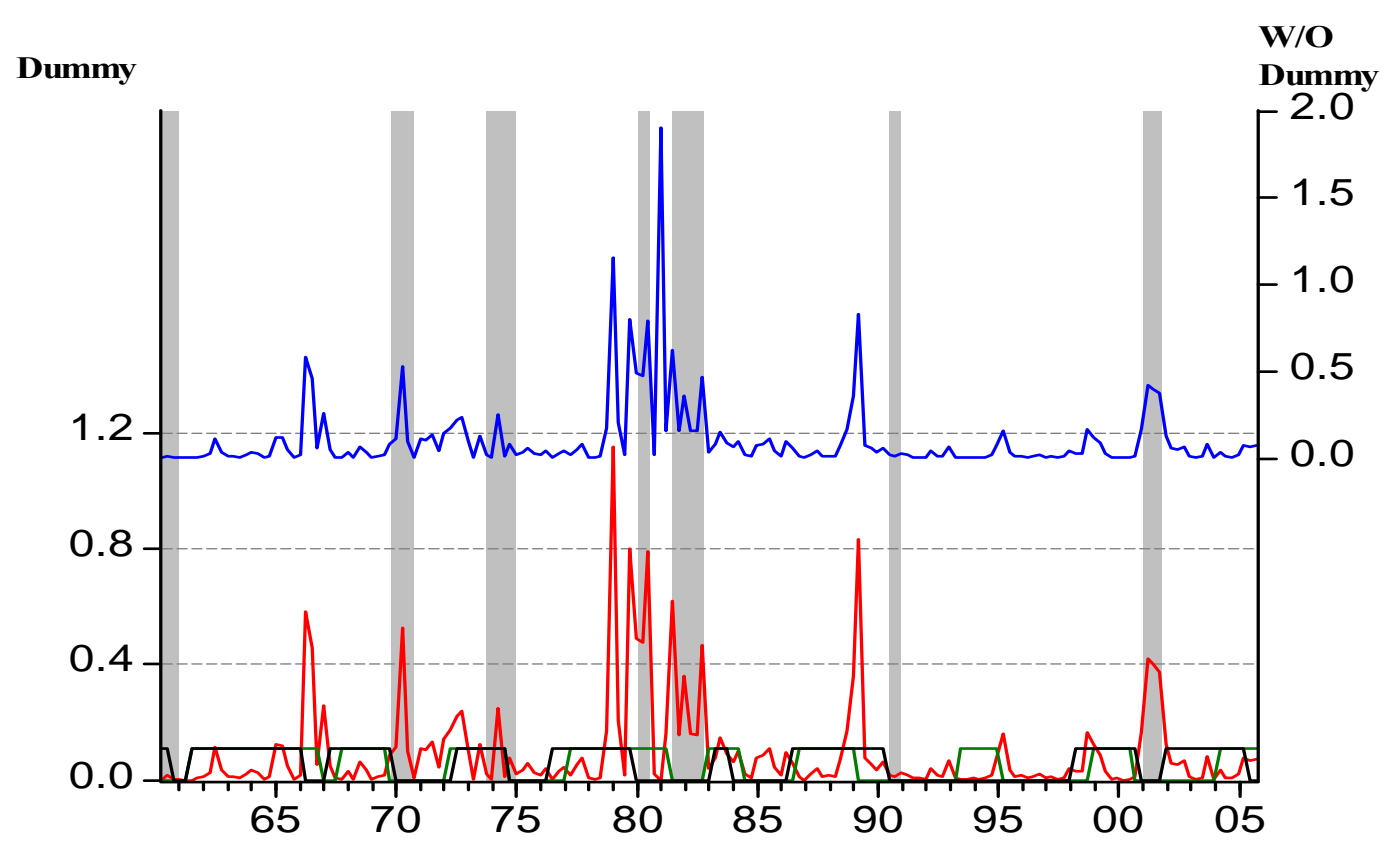


Figure 4e: Difference between Measurement Errors for M3 and MSI3 Growth without $(-)$, and With Dummy (-), High Interest Rate Phases (-), High Inflation Phases (-), and NBER Recessions (Shaded Area)

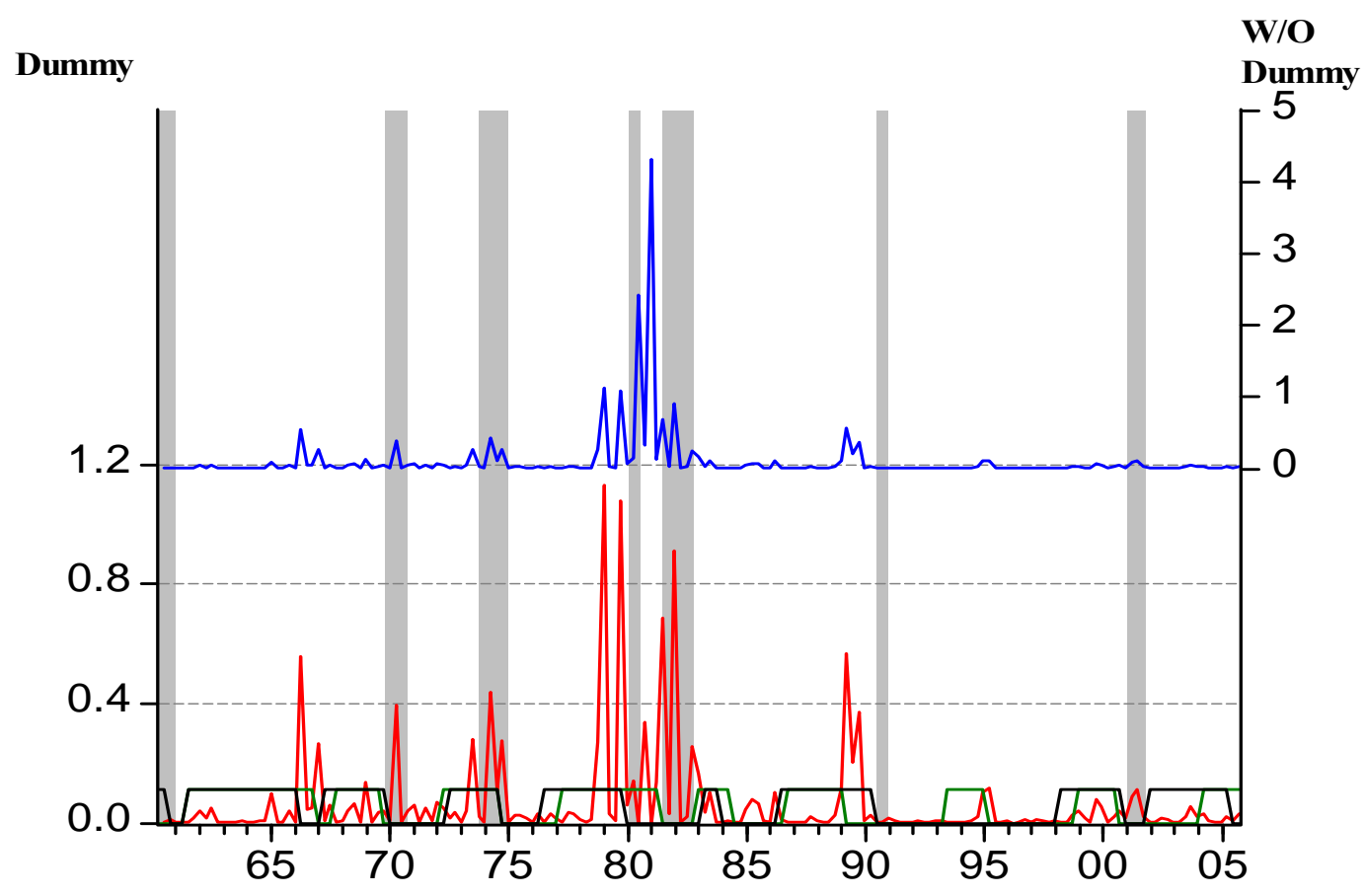

